\title{
Variability of Monsoon Inversion over the Arabian Sea and its Impact on Rainfall
}

Sanjeev Dwivedi ${ }^{1,2}$, Viswanadhapalli Yesubabu ${ }^{1}$, M. Venkat Ratnam ${ }^{1}$, Hari Prasad Dasari ${ }^{3}$, Sabique Langodan ${ }^{3}$, S. T. Akhil Raj ${ }^{1}$, and Ibrahim Hoteit ${ }^{3, *}$

\author{
${ }^{1}$ National Atmospheric Research Laboratory, Gadanki, Andhra Pradesh, India \\ ${ }^{2}$ School of Earth, Ocean and Climate Sciences, IIT Bhubaneswar, India \\ ${ }^{3}$ Physical Sciences and Engineering Division, King Abdullah University of Science and \\ Technology, Thuwal, Saudi Arabia
}

This article has been accepted for publication and undergone full peer review but has not been through the copyediting, typesetting, pagination and proofreading process which may lead to differences between this version and the Version of Record. Please cite this article as doi: $10.1002 /$ joc. 6896 
*Corresponding author: Ibrahim Hoteit, King Abdullah University of Science and Technology (KAUST), Physical Science and Engineering Division, Thuwal 23955-6900, Saudi Arabia. E-mail: ibrahim.hoteit@kaust.edu.sa

\section{Abstract}

This work investigates the spatial and temporal variability of the monsoon inversion (MI) over the Arabian Sea for the study of 37-years period (1980 to 2016) using MERRA version2 (MERRA2) reanalysis and downscaled simulations generated with the Weather and Research Forecasting (WRF) model. After validating the downscaled products with the observations from four radiosonde stations (Salalah, Mumbai, Goa and Mangalore), we analyzed the variability of MI from diurnal to seasonal scales. The diurnal evolution of the MI suggests that radiative cooling over the Arabian Peninsula at night, together with the onset of boundary layer jets along the coast of Oman, play an important role in amplifying the intensity and spatial extent of the MI during night and into the early morning hours. A seasonal analysis of the simulated winds and MI reveals that WRF reproduced the monsoon characteristics as observed in MERRA2 reanalysis, including the spatial and vertical orientations of the MI. The downscaled winds are slightly overestimated (by 1 to $2 \mathrm{~ms}^{-1}$ ) over the Arabian Sea, which resulted in an increased simulated wind shear over the western Arabian Sea, ultimately manifested in the form of an enhanced MI. We further investigated the variability of the lower tropospheric wind speed and associated changes in MI over the 37-year period. This reveals a significant decreasing trend during the summer monsoon over the western Arabian Sea. We argue that this led to a decreasing trend in the lower tropospheric wind shear and advection of temperature, and hence, reduced the frequency of occurrence of the MI (shown in Figure GA).

Keywords: Indian Summer Monsoon, Monsoon Inversion, Monsoon variability, Arabian Sea, WRF Model. 


\section{Introduction}

The Indian summer monsoon (ISM) is one of the most prominent climatic regimes in the global circulation system and plays a critical role in modulating the earth's hydrosphere and biosphere (Wang et al., 2013). The summer monsoon is unique in nature as it transports moisture towards the Indian subcontinent through cross-equatorial winds. The monsoon was initially described as a lower tropospheric phenomenon, mainly driven by thermal and pressure gradients with a prevailing low pressure over the Indian subcontinent and the relatively cooler region of the Mascarene high (Ernest Raj and Deshpande, 2008; Goswami et al., 2005; Wu et al., 2018). Several studies have revealed that the onset of the ISM induces a number of physical and climatological transitions that occur in the lower troposphere and at the ocean surface (e.g. Goswami et al., 2006; Narayanan and Rao, 1981; Muraleedharan et al., 2013; Ramaswamy et al., 2017; Wu et al., 2018; Sooraj et al., 2019).

The formation of thermal inversions over the Arabian Sea is one of such phenomena that significantly regulates the moisture transport towards the Indian landmass (Colon, 1964; Ramage, 1966). Although a weak signal of inversion occurs over the Arabian Sea during the pre- and post-monsoon seasons, the monsoon lifts up the inversion layers laterally from east to west and confines the strengthened inversion to small regions over the Western Arabian Sea (WAS) (Narayanan and Rao, 1981; Ramaswamy et al., 2017). This process of strengthening the inversion layers that is confined over the narrow region above the WAS is referred to as the monsoon inversion (MI) (Colon, 1964). The MI significantly influences the exchange of moisture and energy between the ocean surfaces (Narayanan and Rao, 1981), and is primarily characterized by the temperature gradient and inversion depth over the Arabian Sea (Dwivedi et al., 2016a). The MI index is often quantified based on the gradient method i.e., the difference in temperature between 850 and $950 \mathrm{hPa}$ levels $\left[\Delta \mathrm{T}=\mathrm{T}_{850 \mathrm{hPa}}-\right.$ $\mathrm{T}_{950 \mathrm{hPa}}$ )], and its intensity as the positive value of $\Delta \mathrm{T}$ (Narayanan and Rao, 1981; Dwivedi et al., 2016). Previous studies have linked the formation of the MI during the monsoon to the large-scale evolution of the monsoon low level jet (MLLJ), which induces enhanced upwelling conditions that in turn results in cooler ocean surface conditions over the WAS ( Warnecke et al., 1971; Honjo et al., 1999; Wu et al., 2018; Sooraj et al., 2019). Wu et al. 
(2018) identified MI over the Arabian Sea based on a stability index criteria defined using the potential temperature differences between 1000 and $700 \mathrm{hPa}$. Based on which they mainly related the MI to the monsoon subsystems over Africa, Asia and Northwest Pacific and established a dynamical link between the adjacent monsoons in West Africa and the intensification of MI. The analysis of Wu et al. (2017) suggests that the enhanced heating in the equatorial Indian Ocean and Western North Pacific, and the intensification of the African Monsoon have profound influence on the formation and intensification of MI over the Arabian Sea in August. This dynamical link of MI with the West African monsoon is also supported by the numerical experiments of Sooraj et al. (2019). The other important factors in the intensification of MI are Levar winds over eastern Iran. These are strong northerly winds channeled through the mountains of eastern Iran and Hindu Kush, and their prevalence over north-western Arabian Sea are mainly seen at 800-700 levels (Rashki et al., 2012; Kaskaoutis et al., 2015).

Several studies e.g. Nair et al. (2015) and Abish and Mohanakumar (2011) clearly indicated that the manifestation of MI occurs well above the boundary layer; mainly due to the advection of warm air from the Arabian Peninsula which takes over the maritime MLLJ winds. These westerly winds also known as 'Shamal winds', and are mainly triggered by the pressure difference between the monsoon heat low and the high pressure over the Mediterranean region (Gadgil and Joseph, 2003; Gadgil, 2018). Over western Arabian Sea, the intrusion of warm, dry and dust-laden Shamal winds prevail at $850 \mathrm{hPa}$, flowing above the cold moist monsoon air mass (950-900 hPa) that triggers the development of positive lapse rates over the WAS, leading to the formation of inversion layers (Ramaswamy et al., 2017). By analyzing the temperature profiles of IASI sounder, Dwivedi et al., (2016b) showed that warmer conditions mainly prevail between the 900-850 hPa pressure levels and established a temperature - based criterion (950-850 hPa) for detecting MI after a detailed examination of $\Delta \mathrm{T}$ at several locations and considering all lower tropospheric levels (viz. 1000-900, 1000-850 hPa, etc.). However, the stability index considered by Wu et al. (2018) based on potential temperature, i.e. Theta $(\Theta)$ between surface and $700 \mathrm{hPa}$, may potentially average out these features. 
The positive lapse rate layers of MI alter the gravitational stability of monsoon convection and suppress the favorable conditions for producing rain over the WAS (Muraleedharan et al., 2013). The stable stratified thermal inversion layers over the WAS play a dominant role in trapping the moisture in the lower troposphere, as the MI constrains vertical growth of cloud and acts as a lid for cumulus convection (Narayanan and Rao, 1989) over WAS. When the MI breaks up over the Eastern Arabian Sea (EAS), an enormous amount of trapped moisture is released, triggering deep convection over the west coast of India and the Indian subcontinent. The MI also acts as an atmospheric waveguide by transporting trapped moisture towards the Indian subcontinent (Narayanan and Rao, 1981; Muraleedharan et al., 2013). Swathi et al. (2018) recently reported that the variation of the MLLJ, and the associated changes in the position, strength and height of the inversion zone over the Arabia Sea, strongly modulates the variability of rainfall over the west coast of India. Though past studies suggested that the presence of MI is typically confined over the WAS, several studies (Muraleedharan et al., 2013; Swathi et al., 2018) have recently shown that the MI has been shifting eastwards towards the Eastern Arabian Sea (EAS) and the Indian peninsula, persisting over prolonged periods, specifically during the active monsoon phases ( Ghosh et al., 1978; Pedgley et al., 1966; Bhat, 2006a,b).

Although the formation and progression of the MI has been extensively investigated, its climatological structure and variability during the active and break spells of the monsoon are yet to be described. Ghosh et al. (1978) used radiosonde data collected during the INDO USSR monsoon experiment to reveal that the longitudinal height (at $11^{\circ} \mathrm{N}$ ) of the MI varies substantially during the active phase of the monsoon and is confined to low altitudes over the WAS. This study also established that the MI gradually weakens and ascends in altitude as it approaches the west coast of India. It further reported that the evaporation rate over the Arabian Sea exceeds precipitation and the formation of the MI over the WAS plays a dominant role in altering rainfall patterns over the west coast of India. Muraleedharan et al. (2013) described the characteristics of the MI using radiosonde collected at Goa during the active and break cycles of two contrasting monsoon years (2009 and 2010). They revealed a lower tropospheric thermal inversion with significant strength over the west coast of India 
during the active phase of the monsoon, which disappears with the weakening of the MLLJ during the break cycles. Dwivedi et al. (2016a) investigated the relationship between the shifting and strengthening of the MI and rainfall intensity over central India during the strong and weak monsoon years and reported a stronger MI during weak monsoon years.

Few studies have investigated the variability and factors that influence the MI, such as the impact of intensification of the MLLJ and the Shamal jet (e.g., Aneesh and Sijikumar, 2016; Yu et al., 2016). The Shamal jet is most intense during July, coinciding with the maximum intensity of the MI and the monsoon (Yu et al., 2016). A significant decrease in the $850 \mathrm{hPa}$ winds over the northern Arabian Sea causes a weakening of the wind shear between the surface and $850 \mathrm{hPa}$ (Aneesh and Sijikumar, 2016), which in turn reduces the intensity of the MI. In addition, the shifting of the monsoon jet towards the northern Arabian Sea can reduce the spatial extent and strength of the MI due to the advection of cooler air from the southwest, which reduces the inversion strength over the central and southern Arabian Sea.

Previous studies on MI depended on available observational and satellite derived profiles over a limited period (3-5 years). The lack of long-term in-situ data over this oceanic region hindered so far a detailed analysis of MI and previous studies pointed out to the need of high spatial-vertical resolution data to understand it's climatology and variability (e.g., Bhat, 2006a; Dwivedi et al., 2016a;Dwivedi et al., 2019; Narayanan et al., 2004). This study fills this gap by making use of a regional climate model dataset at high spatial and vertical resolutions. We explore the climatology of the MI in terms of height, strength and frequency of occurrence using Modern-Era Retrospective Analysis for Research and Applications version-2 (MERRA2) reanalysis data and high resolution dynamically downscaled and assimilative WRF simulations over a 37-year period (1980 to 2016). Specifically, we develop a climatological framework of diagnostic analysis by relating features of the thermal inversion with the winds of tropics and monsoonal origins. Moreover, the availability of hourly data enabled us to analyze the diurnal variability of MI, which has not been considered in previous studies. The main objectives of this study are: (i) compare the dynamically downscaled profiles of temperature and wind with radiosonde data to demonstrate their 
relevance in depicting the climatic features of the MI, (ii) to investigate the formation mechanism of the MI over the Arabian Sea based on 37-year high-resolution data, (iii) describe the spatial and temporal variability of the MI at diurnal to inter-annual scales, and (iv) analyze the trends of MI over the Arabian Sea.

\section{Data and methodology}

This Section describes the observations and reanalysis datasets along with the model configuration, including the downscaling and assimilation methodologies that we employed to generate the high resolution atmospheric fields from 1980 to 2016.

\subsection{Radiosonde Data}

WRF outputs were evaluated against the quality controlled radiosonde data obtained from the NOAA Integrated Global Radiosonde Archive (IGRA). Daily instantaneous radiosonde observations (available at 0000 UTC and 1200 UTC) of temperature, humidity and wind were obtained from IGRA over the 37 years simulation period (1980 to 2016). Four radiosonde stations, namely Salalah $\left(17.05^{\circ} \mathrm{N}, 54.11^{\circ} \mathrm{E}\right)$, Mumbai $\left(19.12^{\circ} \mathrm{N}, 72.85^{\circ} \mathrm{E}\right)$, Goa $\left(15.29^{\circ} \mathrm{N}\right.$, $74.12^{\circ} \mathrm{E}$ ) and Mangalore $\left(12.91^{\circ} \mathrm{N}, 74.85^{\circ} \mathrm{E}\right.$ ) are selected for the validation and analysis (as indicated in Fig. 1). A detailed description of IGRA data can be found in Durre et al., (2006) and Durre and Yin, (2008).

\subsection{TRMM 3B42-V7 Rainfall Product}

The multi-satellite merged precipitation from Tropical Rainfall Measuring Mission (TRMM 3B42-V7, Huffman et al., 2007) is used to evaluate against the downscaled rainfall. This rainfall product is available at a horizontal resolution of $0.25^{\circ} \times 0.25^{\circ}$ from 1998 onwards at two temporal resolutions: 3 hourly and daily. Several studies, e.g. Ebert et al., (2007), Prakash et al., (2015), Thakur et al., (2018), highlighted the quality and advantages of using this dataset for climate and monsoon research. In this work, we used the daily product of TRMM 3B42-V7 rainfall available over the period (1998-2016). 


\subsection{WRF Simulations}

We used the Advanced Research WRF model version 3.9.1 configured with a single domain, with a horizontal resolution of $18 \mathrm{~km}$ and 51 vertical layers; the top of the model was fixed at 30 hPa (Skamarock et al., 2008; Viswanadhapalli et al., 2019). The following combination of physical parameterization schemes was used: Thompson et al. (2008) for cloud microphysical process, RRTMG for long wave and shortwave radiation process (Iacono et al., 2008), YSU non-local scheme (Hong and Pan, 1996; Hong and Dudhia, 2004) for planetary boundary layer turbulence, Betts-Miller-Janjić (BMJ) for cumulus convection (Janjić, 1994), and the NOAH MP scheme for land surface processes (Niu et al., 2011). These parameterization schemes were selected based on a number of modelling studies on the monsoon and heavy rainfall over India (e.g. Srinivas et al., 2013; Attada et al., 2018; Chen et al., 2001; Jiang et al., 2009; Reshmi et al., 2018; Srinivas et al., 2018).

To mitigate the uncertainties arising from regional continuous simulations, we followed the approach of consecutive re-initialization to reproduce the spatial and temporal variability of different atmospheric parameters (e.g., Lo et al., 2008; Lucas-Picher et al., 2013; Langodan et al., 2016; Viswanadhapalli et al., 2017; Ratna et al.; 2017; Dasari et al., 2019). The WRF model was initialized on daily basis at 1200 UTC and integrated up to 36hours using the ERA-Interim (ERAI) reanalysis (Dee et al., 2011). The boundary conditions were also extracted from ERAI and were updated every six hours. To improve the land sea representation, the SST available in the coarse resolution lower boundaries of the ERAI data was replaced with a time varying high resolution SST from the Real-Time Global HighResolution SST (RTG-SST; Genmill et al., 2007). All available conventional observations from NCEP Atmospheric Data Project over the initial 12-hour period were assimilated into using a cyclic three-dimensional variational (3DVAR) approach with \pm 3 hour assimilation window; the resulting conditions are then used for subsequent 24 hours forecasts. Considering the first 12-hours of simulation as model spin up, we combined the remaining 24-hour outputs from each simulation to generate a single 37-year climate dataset. To study the variability and trends in the intensity of MI, we considered two distinct regions (shown in Figure 1) over the Arabian Sea: the Western Arabian Sea (WAS, $17^{\circ} \mathrm{N}-20^{\circ} \mathrm{N}$ and $58^{\circ} \mathrm{E}-$ 
$61^{\circ} \mathrm{E}$ ) and the Eastern Arabian Sea (EAS, $17^{\circ} \mathrm{N}-20^{\circ} \mathrm{N}$ and $69^{\circ} \mathrm{E}-72^{\circ} \mathrm{E}$ ) as adopted in recent MI studies (e.g., Dwivedi et al., 2016b).

\subsection{MEERA2 and ERAI Data}

Since the initial and boundary conditions of WRF are provided by ERAI data, there is a possibility to inherit parent model features (i.e. ERAI) in the downscaled simulations. To assess the impact of dynamical downscaling against an independent dataset, we have used MERRA2 along with ERAI. More specifically, we utilized the wind and temperature of MERRA2 at the lower pressure levels $(1000 \mathrm{hPa}$ to $600 \mathrm{hPa})$ with a horizontal resolution of $0.5^{\circ}$ x $0.5^{\circ}$ (Gelaro et al., 2017).

\subsection{Methodology}

We used the radiosonde data to complement the model simulations of the long-term dynamics of the monsoon inversion height. We first removed erroneous measurements from the radiosonde data using a quality check filter, basically removing the measurements that were away more than twice the standard deviation of the mean. The inversion heights are identified based on the gradient method described in Seidel et al. (2010), using various parameters such as temperature, relative humidity $(\mathrm{RH})$, refractivity, etc. The maximum positive/negative value of vertical gradient of the parameter corresponds to the inversion height; see in Seidel et al. (2010) for more details. The MI index is computed based on the gradient method i.e., $\Delta \mathrm{T}\left(\mathrm{T}_{850 \mathrm{hPa}}-\mathrm{T}_{950 \mathrm{hPa}}\right)$, and wind shear $\left(\mathrm{WS}_{850 \mathrm{hPa}}-\mathrm{WS}_{950 \mathrm{hPa}}\right)$. We further used the positive value of MI index to refer to the intensity of MI.

We analyzed the variability of MI based on the 37-year dataset of the dynamically downscaled data and computed statistically significant trends in monsoon inversion and winds using the seasonal Kendall test (SKT) with Sen's slope estimate at a 95\% confidence level (Hirsch et al., 1982; Thas et al., 1998). The SKT accounts for the influence of different periodicities such as semi-annual, annual, ENSO, solar cycles, etc. on trends (Hirsch \& Slack, 1984; Hirsch et al., 1982). For each year, we calculated the daily percentage of occurrences (PO; \%) during June, July, August and September (JJAS; 122 days). 
We analyzed the horizontal heat transport, i.e. advection component between 975 and $700 \mathrm{hPa}$, and the vertical heat transport, i.e. convection/subsidence component between 700 and $400 \mathrm{hPa}$, at individual pressure levels as well as their composite averages. From the thermodynamic energy equation, the expressions for the calculation of advection and subsidence components are derived as follows (Narayanan et al., 2004):

$$
\text { Advection component }=-\left(u \frac{\partial T}{\partial x}+v \frac{\partial T}{\partial y}\right) \times 3600 \mathrm{~K} / \mathrm{hr},
$$

Where $\mathrm{u}$ denotes zonal wind in $\mathrm{ms}^{-1}, \mathrm{v}$ is meridional wind in $\mathrm{ms}^{-1}, \mathrm{~T}$ is temperature in $\mathrm{K}, \mathrm{x}$ and $\mathrm{y}$ are the spatial distance in $\mathrm{m}$. A factor of 3600 was applied to convert to the more convenient unit of $\mathrm{K} / \mathrm{hr}$. Similarly, the convective/subsidence term is expressed as the product of vertical velocity, i.e. omega ( $₫)$, and the local change in temperature with respect to pressure levels.

$$
\text { Convection component }=-\left(\omega \frac{\partial T}{\partial p}\right) \times 3600 \mathrm{~K} / \mathrm{hr},
$$

Where $\mathrm{p}$ denotes pressure in Pa. Positive values of the convection component indicate upward transport (convection), and negative values indicate downward transport (subsidence). Similarly positive values of the advection provide a composite picture of warm air transport over the Arabian Sea, while negative values suggest advection of cold air.

\section{Results and Discussion}

The generated high resolution WRF dataset is first compared against the radiosonde data. The climatology of the wind dynamics and temperature inversions over the Arabian Sea are then analyzed at various scales (diurnal to seasonal) using the WRF outputs and the ERAI and MERRA2 reanalyses. Finally, the variability of the MI on seasonal and associated wind changes is examined.

\subsection{Mean thermal and wind structures}

The comparison of simulated mean JJAS profiles of temperature and wind with radiosonde data shown in Figure 2 at the four selected locations (Salalah, Mumbai, Goa and Mangalore) which suggests that the model is able to capture the observed mean thermal structure. It however slightly overestimates the mean winds in the MLLJ core region by 2-2.5 
$\mathrm{ms}^{-1}$. The temperature profiles from both WRF and radiosonde show significant differences in the lower tropospheric temperatures between the east and west coast stations of Arabian Sea. The west coast station (Salalah) exhibits a typical temperature profile as discussed by Dwivedi et al. (2016b). The mean profile of temperature shows a decreasing pattern from surface up to the height of $1 \mathrm{~km}$, and an increasing pattern between $1.5 \mathrm{~km}$ and $2 \mathrm{~km}$ followed by a decreasing pattern thereafter. The radiosonde stations located in the eastern part of AS exhibit a similar thermal structure at all three stations where the temperature decreases upward. For the downscaled winds, the mean height of MLLJ core is found close to $1 \mathrm{~km}$ ASL while the core height is elevated (by 0.5 to $1 \mathrm{~km}$ ) at the east coast stations. Despite the overestimation of the MLLJ intensity, the model well reproduces the mean structure winds, the core height and the intensity of MLLJ over the west coast station. For the east coast stations, the major deviations in the winds between the model and radiosonde occur in the MLLJ region only. This is probably because the average intensity of MLLJ at the west coast stations $\left(7-8 \mathrm{~ms}^{-1}\right)$ is weaker as compared to the east coast stations $\left(10-11 \mathrm{~ms}^{-1}\right)$, in turn producing a relatively less drift that might result in less errors. The stronger monsoonal winds drift the radiosonde more from the actual location, which amplifies model errors. Since the model simulations were generated on a 18-km grid, a perfect comparison may not be expected in the lower troposphere where steep local gradients over land occur during daytime. Studies like Samson et al. (2014, 2017) suggest that the skill of these downscaled simulations over land if we carried out these WRF simulations in coupled ocean-atmospheric mode over a larger Indian Ocean domain and focusing more on the ocean. A detailed validation of the downscaled parameters presented in previous studies (e.g. Viswanadhapalli et al. 2019; Zaz et al., 2019 and Hima Bindu et al., 2019) suggests that the WRF simulated fields agree well with the observational data and can be used for analyzing the MI.

\subsection{The formation of MI and its monthly variation}

The climatology of the MI is first analyzed based on the 37 years observational radiosonde data and WRF outputs collected at the four selected stations. Figure 3 presents the percentage of occurrence of the thermal inversion height over Salalah for each month, at 0000 UTC from WRF and Radiosonde. The WRF profiles are extracted close to a single grid-point collocated 
with Salalah radiosonde station. MI prevails at higher elevated levels. The height of inversion is stronger during January (and February), with a frequency of 80\%. During JJAS, the inversion heights are mainly confined to the lower tropospheric levels within a narrow band (1 km and $1.25 \mathrm{~km} \mathrm{AGL),} \mathrm{in} \mathrm{contrast} \mathrm{with} \mathrm{the} \mathrm{winter} \mathrm{(November} \mathrm{to} \mathrm{January)} \mathrm{and} \mathrm{pre-}$ monsoon months where MI persists, slightly elevated $(2-2.75 \mathrm{~km})$ or at lowered levels $(0.5$ $1 \mathrm{~km}$ ), respectively. The maximum percentage of occurrence recorded between July and September (70 - $90 \%$ ) suggests that the inversion is stronger during this period at the height level of $1.25 \mathrm{~km}$ AGL where the prevailing north-westerly winds reach its peak. The dustladen, dry and north-westerly winds of Shamal originating from the Arabian peninsula is the primary cause for the frequent MIs at lower tropospheric levels (Kaskaoutis et al., 2015; Ramaswamy et al., 2017). Outside the monsoon season, a weak signal of inversion (between 2 and $3 \mathrm{~km}$ ) is observed over Salalah (10\%) in November, which could be attributed to the onset of the prevailing winds of the winter Shamal flow (Yu et al., 2016) along with the relatively stronger northerly winds at mid-tropospheric levels (800-700 hPa) from eastern Iran (Kamali et al., 2017). The MI height occurs at lower levels $(<2 \mathrm{~km})$ over Karachi, Ahmadabad and Mumbai throughout the year, with a percentage of occurrence varying between 45 and 80\% (figure not shown). An increase in the MI height was observed during JJAS, when the percentage of occurrence of MIs was also at its maximum. We Further evaluated the MI height at 2-3 km over Salalah and Karachi, whereas over Mumbai the inversion height was at $4-5 \mathrm{~km}$ (percentage of occurrence of $5-10 \%$ ), suggesting that the altitude of MI clearly increases during the monsoon season, as has been previously suggested (Colon, 1964; Sikka and Gray, 1981). The climatology analysis confirms the presence of MI during the active phase of monsoon season (July and August).

\subsection{Climatology of MI during Monsoon season}

Several studies (Narayanan et al., 2004; Sikka, 1980) have suggested that the advection of monsoonal winds is the major driving factor in formation of inversions and the height of MI. To understand the formation of the MI, we analyzed the mean pattern of MEERA2, ERAI and WRF winds at $950 \mathrm{hPa}$, and $850 \mathrm{hPa}$ for the ISM months (JJAS). Figure 4 shows the 37-year mean wind speed for JJAS at 950 and $850 \mathrm{hPa}$, as well as the 
lapse rates, i.e., $\Delta \mathrm{T}$ (shaded in color), and the wind shear (vector) between these two pressure levels. MEERA2 winds reveal that the lower troposphere $(950 \mathrm{hPa})$ is dominated by a strong low-level southwesterly flow spreading up to eastern Oman. The influence of the Ekman transport (with increasing wind speed and height) is clearly noticeable at $850 \mathrm{hPa}$, where the low-level south-westerlies are replaced by westerly winds. The void created over the WAS due to the Ekman transport is replaced by the Shamal winds (Figure 4a, b and Figure 4e, f), resulting in high wind shear between these two levels, creating stratified layers with positive lapse rates and an inversion zone over the WAS. Apart from the monsoonal and Shamal winds, orographic channeled south-westerly winds of Red Sea origin are present in the WAS, and the northerly Levar winds (Kaskaoutis et al., 2015; Ramaswamy et al., 2017) are present over the EAS. The downscaled winds capture well the observed wind flow features. Though the ERAI produced similar spatial wind pattern at lower levels (950 hPa), the wind speed of MLLJ at $850 \mathrm{hPa}$ seems to be slightly high (by 1-2 $\mathrm{ms}^{-1}$ ) in ERAI. The intensity of MI $(\Delta \mathrm{T})$ over Arabian Sea from ERAI is significantly less (by $1 \mathrm{~K}$ ) compared to MERRA2. The downscaled WRF produces an improved flow characteristics and thermodynamic structures over the Arabian Sea. The high-resolution model also clearly brings out the terrain/topography effects over the southern Red Sea, Gulf of Aden, eastern Iran and the Western Ghats region which are completely missing in the coarse resolution reanalyzes datasets (Lo et al., 2008; Viswanadhapalli et al., 2017). The downscaled winds over the WAS are slightly overestimated, with higher wind speeds of about 1-2 ms ${ }^{-1}$ compared to MERRA2. Furthermore, the enhanced spatial extent of maximum winds at both pressure levels results in enhanced wind shear and strengthening of the MI in the WRF downscaled simulations. This is probably due to the tendency of the WRF model to overestimate the monsoon winds and rainfall as discussed in Srinivas et al. (2013).

To illustrate the vertical structure and intensity of the MI and winds over the Arabian Sea during JJAS months, we plotted the longitudinal pressure section of 37-year mean (temperature) lapse rates along with horizontal winds at $12^{\circ} \mathrm{N}, 16^{\circ} \mathrm{N}, 20^{\circ} \mathrm{N}$, and $24^{\circ} \mathrm{N}$ from the three datasets (MERRA2, ERAI and WRF), as shown in Figure 5. The lapse rates clearly show the formation of the MI at $975 \mathrm{hPa}$ and above at $57^{\circ} \mathrm{E}$, reaching, its maximum $(<2 \mathrm{k})$ at 
$925 \mathrm{hPa}$ at $60^{\circ} \mathrm{E}, 24^{\circ} \mathrm{N}$. This is in agreement with the MERRA2 and ERAI datasets, which also show the origin of the positive lapse rates, their progression and dissipation over the EAS, and their spread towards the Indian subcontinent. The cross-sectional results show a lower and more intense MI with increasing latitude from $12^{\circ} \mathrm{N}$ to $24^{\circ} \mathrm{N}$, and a higher and less intense MI from the WAS to the EAS (Figure 5), in agreement with Dwivedi et al. (2016). A lapse rate of $-2 \mathrm{~K}$ per $25 \mathrm{hPa}$ is observed over the Arabian Peninsula from 900 to $700 \mathrm{hPa}$, with the positive lapse rates increasing only in the presence of directional shear winds. The intensity of the MI $(\Delta \mathrm{T})$ increased with the increased strength of monsoonal winds, reaching its maximum intensity between 950 to $850 \mathrm{hPa}$. A decrease in the strength and spread of southwesterly winds is also observed with increasing latitude from $12^{\circ} \mathrm{N}$ to $24^{\circ} \mathrm{N}$, together with an increase in the strength and vertical spread of winds from the WAS to the EAS. The northwesterly Shamal winds and north Laver jets become stronger between $12^{\circ} \mathrm{N}$ and $24^{\circ} \mathrm{N}$ over WAS and the central Arabian Sea. As observed in the spatial patterns of winds and $\Delta \mathrm{T}$ for the ERAI, the vertical structures of lapse rates and winds are also in good agreement with MERRA2; however, it produced a weaker positive lapse rates and their vertical extension seems to be confined to lower levels (925 hPa). The effects of topography and mesoscale influence on the formation of the MI are clearly seen with the downscaled simulations over WAS where the lapse rate has significantly high positive values. Overall, the results suggest that the pattern of longitudinal-height section of downscaled wind and lapse rates compare well with MERRA2 data, albeit a slight stronger winds that might have led to increased wind shear and more intense MI in the model.

The formation of thermal inversions tends to inhibit the vertical growth of clouds from western to central Arabian Sea which, ultimately influence the rainfall over the Arabian Sea and adjoining coastal regions (Narayanan, 1981). To illustrate the extent of MI influence on the spatial variability of rainfall and associated factors (such as convective, energy fluxes and thermodynamic instability parameters), we analyze the spatial variation of the simulated parameters of convective available potential energy (CAPE) and convective inhibition (CIN), latent heat and sensible heat fluxes (shown in Figure S1). The CIN and sensible flux exhibit similar patterns as the positive $\Delta \mathrm{T}$ regions. The $\mathrm{CIN}$ is a measure of negative energy that an 
air parcel possesses to inhibit as it is lifted from the surface to a level of free convection and it is an indicator of low level convective instability. The strong negative values of CIN (<$300 \mathrm{~J} / \mathrm{kg}$ ) indicates a weak tendency of convection in the MI dominant regions over WAS. The spatial distributions of CAPE suggest that it may not reflect the spatial influence of MI (Figure S1.a) as it is an indicator for mid-tropospheric instability. The MI signal is partly seen in the spatial distribution of sensible heat flux. This is mainly due to the presence of cooler surface conditions over the MI dominated regions, as the low level monsoon flow induces upwelling conditions over the western Arabian Sea which decreases the transfer of sensible heat flux and leads to cooler surface temperatures.

We have further analyzed the extent of MI influence, the spatial variation of the JJAS rainfall (in mm) from TRMM and WRF (shown in Figure S2). The results suggest that the rainfall distribution over the Arabian Sea follows the patterns of the lapse rate, with a relatively less rainfall $(<50 \mathrm{~mm}$ ) over the north-western Arabian Sea, the spatial rainfall pattern exhibit a steady increase (positive gradient) with decreasing lapse rates over the central Arabian Sea, and a maximum rainfall over EAS. The spatial variation of monthly mean $\Delta \mathrm{T}$ and rainfall shown in Figure 6 suggests that the thermal inversions are maximum in July over WAS and minimum in September, followed by June. Viswanadhapalli et al., (2019) reported the maximum strength of MLLJ winds and the shear between 950 and $850 \mathrm{hPa}$ levels in July, which can be considered as a major factor for reaching the peak intensity of thermal inversions during the same period. During July and August, the monthly rainfall over the Arabian Sea shows the same spatial pattern as seen in lapse rates. The shift in lapse rate (3 to $-3.5^{\circ} \mathrm{C}$ ) pattern towards the east-central Arabian Sea, and its longitudinal alignment (at $\left.65^{\circ} \mathrm{E}\right)$ also matches with the rainfall pattern $(<100 \mathrm{~mm})$. The spatial distributions of lapse rates and rainfall at both seasonal and monthly scales suggest a high correlation between the rainfall and the lapse rates over the Arabian Sea, also the lapse rates greater than $-3^{\circ} \mathrm{C}$ are not favorable for convection and rainfall over Arabian Sea.

\subsection{Role of advection and convection on the intensification of MI}


Narayanan et al., (2004) analyzed the role of temperature in the formation of the MI over the Arabian Sea. They revealed that subsidence of upper tropospheric air and the advection of monsoonal winds are essential ingredients in the formation, strengthening and maintenance of the MI during the break and active phases of the monsoon. To investigate this further, we examined the contribution of advection and convection terms of temperature using the monthly means of 37 years of MERRA2 and WRF data (Figure 7). The monthly composites of advection shown in the left and middle panels of Figure 7 are computed for the individual levels of 975 and $925 \mathrm{hPa}$, respectively, while the monthly composite term of convection/subsidence is calculated using the integrated vertical fields from 700 to $400 \mathrm{hPa}$ (shown in the right panels of Figure 7). The temperature advection in May at low altitudes indicates relatively cooler surface conditions over the Red Sea, the Gulf of Aden and off the coast of Yemen compared to the monsoon. This cooling can be associated with prevailing northwesterly winds from the Mediterranean (Viswanadhapalli et al., 2017). These relatively cooler winds reduce the development of positive lapse rates over the western Arabian Sea during May. The negative convection component over the northern Arabian Sea indicates a predominant role of dry air subsidence during May over the region. Preethi et al. (2011) and Vinoj et al. (2014) suggested that this subsidence plays an important role over the Arabian Sea due to the descent of dry warm air as part of a Hadley cell. Southwesterly winds at the surface $(975 \mathrm{hPa})$ during the monsoon produce cooler temperatures over the western to central Arabian Sea, and relatively warmer temperatures in the central Red Sea and Gulf of Aden. The prevailing strong MLLJ drives an upwelling of cool water over the WAS, which induces strong cooling conditions at the surface. From June to August, the intrusion of hot and dust laden desert winds at lower tropospheric levels (925 hPa) via mountain gaps in the eastern Arabian Peninsula produces warmer conditions over the WAS. This advection of hot desert air prevails from $925 \mathrm{hPa}$ to $700 \mathrm{hPa}$, with an increasing spatial extent from the western to the central Arabian Sea (Figure 8), resulting in the formation of the MI over the Arabian Sea during the monsoon season. Out of the three datasets, ERAI shows a weaker advection compared to MERRA2 and WRF. The WRF simulations clearly show a stronger advection of heat in the lower layers 925 and 975 hPa whereas MERRA2 indicates a stronger advection at 850 and $800 \mathrm{hPa}$ levels. On the other hand, convection dominates over the 
mountainous region of Western Ghats, East Africa, the southwestern Arabian Peninsula and the northern Arabian Sea. The strength of convection is relatively less over the northern Arabian Sea compared to the Western Ghats. This is possibly due to the suppression of convection caused by the presence of positive lapse rates over the northern Arabian Sea, whereas the presence of negative lapse rates over the EAS and strong MLLJ winds enhance orographic convection. During September, both the weakening of Shamal winds and the reduction in the strength of MLLJ drive a significant reduction in the intensity of the MI. Accordingly, temperature advection due to the prevailing winds and the magnitude of convection in September drastically reduces the strength of the MI.

\subsection{Diurnal variability of MI}

To the best of our knowledge, the diurnal variation of winds and its relation to the amplification of the intensity of MI has not been yet investigated because of the lack of availability of high spatio-temporal resolution data (e.g., Dwivedi et al., 2016a; Dwivedi, 2016b). Figure 9 provides a diurnal oscillation of the MI from the coast of the Arabian Peninsula to the north-central Arabian Sea in conjunction with the diurnal patterns of the Shamal and MLLJ winds as indicated by Viswanadhapalli et al. (2019) who showed that the diurnal variation of MLLJ is at maximum strength during daytime and the Shamal winds are enhanced in the night hours. The spatial extension of MI over WAS is minimum during daytime (0600 UTC and 1200 UTC), possibly due to the maximum strength of MLLJ and weakening of the wind shear (shown in Figure 10b \& c) between the two levels (950hPa and $850 \mathrm{hPa}$ ). During nighttime, the extension of MI towards the coast of Oman (Figure 9a \& 9d) is maximum with peak intensity (MI of $3^{\circ} \mathrm{C}$ ) between 1800 and $0000 \mathrm{UTC}$, which may be due to the strengthening of the wind shear between the two levels (950 hPa and $850 \mathrm{hPa}$ ) as shown in Figure 10 a \& d. The diurnal variations of $\Delta \mathrm{T}$ averaged over WAS (shown in Figure S3) clearly shows the existence of diurnal signal in the MI and maximum $\Delta \mathrm{T}$ in the early morning hours (0000 UTC). The formation of nocturnal boundary layer jet winds at $850 \mathrm{hPa}$ along the coast of Oman during the evening hours (Ranjha et al., 2015) is possibly the major factor for enhancing the vertical wind shear which contributes to the strengthening of MI. These nocturnal winds shows a sharp increase in the strength of the Shamal winds over the 
northeastern Arabian Peninsula, producing increased positive lapse rates near the coast and a shift of the MI to the east. This is related to the differential land-sea thermal heating at low levels over the desert surface and Arabian Sea, which triggers coastal boundary layer jets over the coast of Oman (Ranjha et al., 2015). Its extension towards the northeast parts of Oman may result in the shifting of the MI towards the coastal region of Oman, which maximizes its spatial extent in the morning (Du et al., 2015).

The longitudinal-height sections of winds and temperature lapse rates at $20^{\circ} \mathrm{N}$ at 0000 UTC, 0600 UTC, 1200 UTC and 1800 UTC are presented in Figure 11. The diurnal variation of the lapse rates and winds are visible in the longitude vertical cross-section, showing a weakening of the Shamal jet $\left(51^{\circ} \mathrm{E}\right.$ to $\left.60^{\circ} \mathrm{E}\right)$ during the evening hours and strengthening during the night, thus forming nocturnal inversion conditions over the Arabian Peninsula. In addition, the strength of the Shamal winds also decreases slowly as the day progresses (0600 UTC to 1200 UTC), which in turn affects the diurnal cycle of the temperature lapse rates. The lapse rates $\left(2^{\circ} \mathrm{K}\right.$ per $\left.25 \mathrm{hPa}\right)$ slowly increase at $1800 \mathrm{UTC}$ in the low levels (Figure 11) and reach a maximum in the early morning hours (0000 UTC), before its subsequently weakens as the day progresses. This suggests that the diurnal variability of the Shamal jet has a direct impact on the diurnal cycle and intensity of the MI, with a maximum at $1800 \mathrm{UTC}$ and $0000 \mathrm{UTC}$ over the WAS $\left(60^{\circ}\right.$ to $\left.65^{\circ} \mathrm{N}\right)$ and a minimum at 1200 UTC, i.e., 3:00 local time (AST). Moreover, the height of the MI seems to increase during the daytime when the MLLJ reaches its peak strength, while the longitudinal extension of MI is at its maximum during the nighttime. The near surface (975 to $925 \mathrm{hPa}$ ) low-level inversions over the EAS are at their minimum at 0000 and 0600 UTC, but start to increase at 1200 UTC and 1800 UTC. In addition, the lapse rates are minimum, equal to $2 \mathrm{~K}$ per $25 \mathrm{hPa}$ up to a height of $750 \mathrm{hPa}$ over the Western Ghats at $1200 \mathrm{UTC}$, and start to increase both vertically and longitudinally (extending eastwards) until reaching a maximum at 0000 UTC. This process may be associated with low-level jets flowing through the mountains gaps of Western Ghats that reach maximum wind speeds at night. This results in a distinct diurnal cycle of MLLJ over Western Ghats compared to the large-scale MLLJ as reported by Nair et al., (2015) and Prabha et al., (2011). This suggests that the diurnal patterns of winds and 
inversions over the WAS with maximum intensity at 0000 UTC is similar to that of the Arabian Peninsula and this pattern seems to vary with the diurnal pattern of MI over the Arabian Sea.

\subsection{Trends in MI}

Several studies have suggested that the MLLJ winds have strengthened and the moisture transport from the Arabian Sea has increased starting from 1999 (e.g., Krishnamurthy and Ajayamohan, 2010; Wang et al., 2013). To examine the long-term trends of both the MI, MLLJ and Shamal jet, we performed a spatial trend analysis on the MI and the factors affecting it (Figure 12). While computing the spatial trends, we applied the seasonal Mann Kendall test that describes the trend while filtering out the seasonal effect on the variability (Belle et al., 1984; Hirsch et al., 1982; Hirsch and Slack, 1984). The spatial trends of the SLP, wind shear and MI over the Arabian Sea are presented in Figure 12. All computed trends are significant at 95\% confidence level (marked by black dots). The spatial trends of SLP from ERAI and WRF suggest similar spatial patterns of trends, except over the eastern Arabian Peninsula, decreasing tendencies over the eastern part of the Arabian Sea and West coast of India, and increasing tendencies over Pakistan and the eastern parts of Iran. The trends in the wind shear between the two levels (950 hPa and $850 \mathrm{hPa}$ ) indicate increasing tendencies for MLLJ from the central Arabian Sea to the equatorial Indian Ocean and decreasing shears over the northern Arabian Sea. To further understand the cause for these changes in the wind shear, we analyzed the spatial trends of winds at two different levels, 950 $\mathrm{hPa}$ and $850 \mathrm{hPa}$ (shown in Figure S4), which showed a definite increasing trend in the intensity of MLLJ from the Somali coast to the west-central Indian Ocean at both levels. Moreover, the spatial trends of winds at 950-hPa clearly indicate significant decreasing tendencies over the eastern parts of AP and west to north parts of the Arabian Sea. This is probably due to the increased tendencies over Pakistan and the eastern parts of Iran, which in turn reduces the pressure gradient between the heat low over Pakistan and Mediterranean region, causing a reduction in the strength of the north-westerly flow over the eastern AP and WAS at lower tropospheric levels. These trend changes in the winds are likely affecting the trends in MI. The spatial trend analysis of MI clearly shows a significant decreasing trend of 
the MI over the central Arabian Sea and the WAS, and an increasing trend near the Somalia region and in the southern Indian Ocean (bottom panels of Figure 12).

To illustrate the variability of the MI and the decreasing tendencies of winds precisely over the WAS and EAS, we averaged the time series of daily Percentage of Occurrence (PO) and temperature lapse rates of the MI and presented their trends during the monsoon season (Figure 13). The trends in temperature lapse rates indicate a decreasing intensity of the MI of about $0.017 \mathrm{~K}$ and $0.014 \mathrm{~K}$ per year over the WAS and EAS, respectively (Figure 13a). The trend of the daily PO suggests that the number of inversion days was reduced by $20-30$ days (15 - 30 \%) over the past 37 years over the WAS. The decrease in the strength and daily PO of the MI suggests a statistically significant change over the central and western India. The time series of the averaged downscaled wind speeds over the WAS and EAS (Figure S5) suggest that these winds have been strengthening over the EAS, whereas a decreasing trend is noticeable over the WAS (95\% of confidence at both pressure levels). The winds over the EAS show a strong increasing trend at $850 \mathrm{hPa}\left(+0.007 \mathrm{~ms}^{-1}\right.$ per year $)$ and $950 \mathrm{hPa}(+0.016$ $\mathrm{ms}^{-1}$ per year). On the other hand, a decreasing trend at $850 \mathrm{hPa}\left(-0.007 \mathrm{~ms}^{-1}\right.$ per year) and $950 \mathrm{hPa}\left(-0.031 \mathrm{~ms}^{-1}\right.$ per year) is noticeable over the WAS. In general, the trend is more significant at lower tropospheric levels compared to the $850 \mathrm{hPa}$ level as seen in the spatial trend analysis. Our results suggest that the intensification of the monsoon circulation and the weakening of the Shamal winds could be the major factors behind the observed decreasing tendency of the MI intensity and daily PO of the MI.

\section{Summary and Conclusions}

Thermal inversions in the lower troposphere over the Arabian Sea are semi-permanent atmospheric phenomena that commonly appear during the pre-monsoon season. These inversions intensify and spread over a wider region of the WAS with the onset of the Indian summer monsoon, and are referred to as monsoon inversions (MI). In the WAS, the intrusion of hot desert air over the cold and moist monsoonal air mass enhances the gravitational stability of the layered air masses, forming stable stratified layers. However, much remains to be understood about the formation and persistence of MI and the extent of their impact on the 
Indian summer monsoon. Here, we studied the climatology and variability of these inversions over the WAS and EAS using regional dynamical downscaled simulations and MERRA2 reanalysis datasets. Prior to the analysis of the MI, we validated our downscaled WRF model simulations using radiosonde observations at four selected location. The comparison of our model simulations with the observed radiosonde data demonstrated that our model outputs reproduce reasonably well with the observed temperature, humidity and wind profiles. The downscaled winds of the WRF model further well captured the observed features of monsoon wind flows and the pattern of temperature lapse rates (as extracted from MERRA2 reanalysis data), with a slight overestimation of the observed wind speed (by $\sim 1 \mathrm{~ms}^{-1}$ ). Our analysis suggests that this slight overestimation increase in the simulated wind speeds may have enhanced the wind shear over the WAS, causing an intensification of the simulated MI over the Arabian Sea compared to MERRA2. We investigated the short and long term variability of all the factors that affect the stability and duration of the MI, including the different wind regimes. The major conclusions of our study can be summarized as follows:

1. The analysis of temperature advection and convection at different lower tropospheric levels suggests that the advection of hot desert air (the dust laden north-to-northwesterly winds of the Shamal and Levar origin at mid-tropospheric levels) spreads across the western and central Arabian Sea. This creates a wind shear anomaly and temperature advection that supports the formation and the prolonged maintenance of the MI over the WAS.

2. The diurnal variation of winds show a maximum strength of the MLLJ during daytime and an enhancement of Shamal winds, coinciding with peak intensity of MI over the northern Arabian Peninsula. Radiative cooling over the Arabian Peninsula at nighttime, along with the onset of boundary layer jets along the coast of Oman, seems to play a dominant role in the development of maximum wind speeds and their spatial extension.

3. The analysis of winds and atmospheric inversions clearly suggests that the diurnal variability of the MLLJ and the Shamal jet has a direct impact on the diurnal evolution and intensity of inversions over the WAS at nighttime. The evolution of the 
wind and MI diurnal cycles over the Arabian Sea suggests that winds over the sea exhibit distinct characteristics compared to the Arabian Peninsula.

4. The diurnal pattern of winds and inversions over the WAS differs from that over the Western Ghats. Whereas the MI over the Arabian Sea is more intense, confined to lower altitudes and largely controlled by variations of the MLLJ and the Shamal winds, inversions over Western Ghats and the Indian subcontinent are weakened and shifted to higher altitudes, and their diurnal cycle is mainly influenced by the topography of the Western Ghats.

5. A definite decreasing trend was identified in the lower tropospheric winds, which may be the cause of the observed decreasing trend in the frequency of occurrence of the MI over the WAS.

We conclude that the decreasing trend in MI strength and occurrence during the peak monsoon season is due to the weakening of winds over the WAS. Previous observational studies (Saha et al., 2014a; Turner and Annamalai, 2012) have reported a decreasing trend in Indian summer monsoon rainfall. The MI over the Arabian Sea can act as a barrier, trapping moisture and enhancing its moisture budget for the Indian summer monsoon, and thus increasing rainfall. The statistical relationships between the MI and ISM need to be established in the context of the large scale monsoon circulation and will be explored in our futures studies. Our results provide a guideline for future climate-change studies taking into consideration the development and impact of thermal inversions on the Indian summer monsoon.

\section{Acknowledgements}

Dr S. Dwivedi acknowledges the funding provided by the Science and Engineering Research Board (SERB), Department of Science \& Technology (DST), Government of India for through grant number PDF/2016/003854. Dr. Hariprasad Dasari and Sabique Langodan acknowledge funding from Saudi Arabian Companies, Saudi Arabia. The research made use of the Supercomputing facility 'SHAHEEN' at King Abdullah University of Science and Technology (KAUST), Saudi Arabia.

\section{References}


Abish B, Mohanakumar K. 2011. Role of fine mode aerosols in modulating cloud properties over industrial locations in north India. Annales Geophysicae, 29(9), 1605-1612. DOI: 10.5194/angeo-29-1605-2011.

Aneesh S, Sijikumar S. 2016. Changes in the south Asian monsoon low level jet during recent decades and its role in the monsoon water cycle. Journal of Atmospheric and SolarTerrestrial Physics, 139, 47-53.

Attada R, Kumar P, Dasari HP. 2018. Assessment of Land Surface Models in a HighResolution Atmospheric Model during Indian Summer Monsoon. Pure and Applied Geophysics, 175, 1-26.

Belle VG, Hughes JP. 1984. Nonparametric Tests for Trend in Water Quality. Water Resources Research, 20(1), 127-136.

Bhat GS. 2006a. The Indian drought of 2002--A sub-seasonal phenomenon? Quarterly Journal of the Royal Meteorological Society, 132(621), 2583-2602.

Bhat GS. 2006b. Near-surface temperature inversion over the Arabian Sea due to natural aerosols. Geophysical Research Letter,. 33(2): 2-5.

Chen F, Dudhia J. 2001. Coupling an Advanced Land Surface-Hydrology Model with the Penn State-NCAR MM5 Modeling System. Part II: Preliminary Model Validation. Monthly Weather Review, 129(4), 587-604.

Colon JA. 1964. On interactions between the southwest monsoon current and the sea surface over the Arabian Sea. Indian Journal of Meteorology Hydrology and Geophysics, 15, 183200.

Dasari HP, Desamsetti S, Langodan S, Attada R, Kunchala RK, Viswanadhapalli Y, Knio O, Hoteit I. 2019. High-resolution assessment of solar energy resources over the Arabian Peninsula. Applied Energy, 248, 354-371. DOI:10.1016/j.apenergy.2019.04.105.

Dee DP, Uppala SM, Simmons AJ, et al. 2011. The ERA-Interim reanalysis: Configuration 
and performance of the data assimilation system. Quarterly Journal of the Royal Meteorological Society, 137(656), 553-597.

Du Y, Chen Y-L, Zhang Q. 2015. Numerical Simulations of the Boundary Layer Jet off the Southeastern Coast of China. Monthly Weather Review, 143(4), 1212-1231.

Durre I, Vose RS, Wuertz DB. 2006. Overview of the Integrated Global Archive. Journal of Climate,19(1), 53-68.

Durre I, Yin X. 2008. Enhanced radiosonde data for studies of vertical structure. Bulletin of the American Meteorological society, 89(9), 1257.

Dwivedi S. 2016. Investigations on low level Indian summer monsoon inversion. SRM University, Chennai.

Dwivedi S, Narayanan MS, Venkat Ratnam M, Narayana Rao D. 2016a. Characteristics of monsoon inversions over the Arabian Sea observed by satellite sounder and reanalysis data sets. Atmospheric Chemistry and Physics, Copernicus Publications, 16(7), 4497-4509.

Dwivedi S, Sathiyamoorthy V, Narayanan MS, Narayana Rao D. 2016b. A Study on the Lower Tropospheric Thermal Inversion over the Arabian Sea Using Radiosonde and IASI Data. IEEE Journal of Selected Topics in Applied Earth Observations and Remote Sensing, 9(1), 490-495.

Dwivedi S, Uma R, Lakshmi Kumar TV, Narayanan MS, Pokhrel S, Kripalani RH. 2019. New spatial and temporal indices of Indian summer monsoon rainfall. Theoretical and Applied Climatology, 135(3-4), 979.

Ebert EE, Janowiak JE, Kidd C. 2007. Comparison of Near-Real-Time Precipitation Estimates from Satellite Observations and Numerical Models. Bulletin of the American Meteorological Society 88(1): 47-64. DOI: 10.1175/BAMS-88-1-47.

Ernest Raj P, Deshpande SM. 2008. Pre-monsoon to monsoon change in direction of vertical motions in the tropical lower troposphere from UHF radar observations. Geophysical Research Letter, 35(15), 6-9. 
Gadgil S. 2018. The Monsoon System: Land-sea breeze or the ITCZ? Journal of Earth System Science, 127(1), 1-29.

Gadgil S, Joseph PV. 2003. On breaks of the Indian monsoon. Proceedings of the Indian Academy of Sciences, Earth and Planetary Sciences, 112(4), 529-558.

Gemmill W, Katz B, and Li X. 2007. Daily real-time, global sea surface temperature-Highresolution analysis: RTG_SST_HR. NOAA/NWS/NCEP/ EMC/MMAB, Science Application International Corporation, and Joint Center for Satellite Data Assimilation Tech. Note 260, 22 pp.

Ghosh SK, Pant MC, Dewan BN. 1978. Influence of the Arabian Sea on the Indian summer monsoon. Tellus, 30(2), 117-125.

Goswami BN, Venugopal V, Sangupta D, Madhusoodanan MS, Xavier PK. 2006. Increasing trend of extreme rain events over India in a warming environment. Science, 314(5804), 14421445.

Goswami BN, Xavier PK. 2005. ENSO control on the south Asian monsoon through the length of the rainy season. Geophysical Research Letters, 32(18), L18717, doi:10.1029/2005GL023216.

Hima Bindu H, Venkat Ratnam M, Yesubabu V, Dasari HP. 2019. Medium frequency gravity wave characteristics obtained using Weather Research and Forecasting (WRF) model simulations. Journal of Atmospheric and Solar-Terrestrial Physics, 182, 119-129.

Hirsch RM, Slack JR. 1984. A Nonparametric Trend Test for Seasonal Data With Serial Dependence. Water Resources Research, 20(6), 727-732.

Hirsch RM, Slack JR, Smith RA. 1982. Trend Analysis for Monthly Water Quality Data. Water Resources Research, 18(1), 107-121.

Hong S-Y, Pan H-L. 1996. Nonlocal Boundary Layer Vertical Diffusion in a Medium-Range Forecast Model. Monthly Weather Review, 124, 2322-2339. 
Hong SY, Dudhia J. 2004. Testing of a new nonlocal boundary layer vertical diffusion scheme in numerical weather prediction applications. Bulletin of the American Meteorological Society, 2(1), 2213-2218.

Honjo S, Dymond J, Prell W, Ittekkot V. 1999. Monsoon-controlled export fluxes to the interior of the Arabian Sea. Deep-Sea Research Part II: Topical Studies in Oceanography, 46(8-9), 1859-1902.

Huffman GJ, Bolvin DT, Nelkin EJ, Wolff DB, Adler RF, Gu G, Hong Y, Bowman KP, Stocker EF. 2007. The TRMM Multisatellite Precipitation Analysis (TMPA): Quasi-Global, Multiyear, Combined-Sensor Precipitation Estimates at Fine Scales. Journal of Hydrometeorology 8(1): 38-55. DOI: 10.1175/JHM560.1.

Iacono MJ, Delamere JS, Mlawer EJ, Shephard MW, Clough SA, and Collins WD. 2008. Radiative forcing by longlived greenhouse gases: calculations with the AER radiative transfer models. Journal of Geophysical Research, 113, D13103. doi:10.1029/2008JD009944.

Janjić ZI. 1994. The Step-Mountain Eta Coordinate Model: Further Developments of the Convection, Viscous Sublayer, and Turbulence Closure Schemes. Monthly Weather Review, 122(5), 927-945.

Jiang H, Farrar JT, Beardsley RC, Chen R, Chen C. 2009. Zonal surface wind jets across the Red Sea due to mountain gap forcing along both sides of the Red Sea. Geophysical Research Letters, 36(19), 1-6.

Kamali S, Mofidi A, Zarrin A, Nazaripour H. (2017) Sensitivity studies of the forthgeneration regional climate model simulation of dust storms in the Sistan plain, Iran. Model. Earth Syst. Environ, 3, 769-781. https://doi.org/10.1007/s40808-017-0333-9

Kaskaoutis DG, Rashki A, Houssos EE, Mofidi A, Goto D, Bartzokas A, Francois P, Legrand M. 2015. Meteorological aspects associated with dust storms in the Sistan region, southeastern Iran. Climate Dynamics, 45(1-2), 407-424.

Krishnamurthy V, Ajayamohan RS. 2010. Composite structure of monsoon low pressure 
systems and its relation to Indian rainfall. Journal of Climate, 23(16), 4285-4305.

Langodan S, Viswanadhapalli Y, Dasari HP, Knio O, Hoteit I. 2016. A high-resolution assessment of wind and wave energy potentials in the Red Sea. Applied Energy, 181, 244255.

Lo JCF, Yang ZL, Pielke RA. 2008. Assessment of three dynamical climate downscaling methods using the Weather Research and Forecasting (WRF) model. Journal of Geophysical Research Atmospheres, 113(9). https://doi.org/10.1029/2007JD00921

Lucas-Picher P, Boberg F, Christensen JH, Berg P. 2013. Dynamical Downscaling with Reinitializations: A Method to Generate Finescale Climate Datasets Suitable for Impact Studies. Journal of Hydrometeorology, 14(4), 1159-1174.

Mlawer EJ, Taubman SJ, Brown PD, Iacono MJ, Clough SA. 1997. Radiative transfer for inhomogeneous atmospheres: RRTM, a validated correlated-k model for the longwave. Journal of Geophysical Research: Atmospheres, 102(D14), 16663-16682.

Muraleedharan PM, Mohankumar K, Sivakumar KU. 2013. A study on the characteristics of temperature inversions in active and break phases of Indian summer monsoon. Journal of Atmospheric and Solar-Terrestrial Physics, 93, 11-20.

Nair SK, Prabha TV, Purushothaman N, Sijikumar S, Muralidharan S, Kirankumar NVP, Subrahamanyam DB, Anurose TJ, Prijith SS, Namboodiri KVS. 2015. Diurnal variations of the low-level jet over peninsular India during the onset of Asian summer monsoon. Theoretical and Applied Climatology, 120(1-2), 287-298.

Narayanan MS, Rao BM. 1981. Detection of monsoon inversion by TIROS-N satellite. Nature, 294, 546-548.

Narayanan MS, Rao BM. 1989. Stratification and convection over Arabian Sea during monsoon 1979 from satellite data. Proceedings of the Indian Academy of Sciences-Earth and Planetary Sciences, 98(4), 339-352. 
Narayanan MS, Rao BM, Shah S, Prasad VS, Bhat GS. 2004. Role of atmospheric stability over the Arabian Sea and the unprecedented failure of monsoon 2002. Current Science, 86(7), 938-947.

Niu G-Y, et al. 2011. The community Noah land surface model with multiparameterization options (Noah-MP): 1. Model description and evaluation with local-scale measurements, $J$. Geophys. Res., 116, D12109, doi:10.1029/2010JD015139.

Pedgley DE. 1966. The Red Sea Convergence Zone. Weather, 21(10), 350-358.

Prabha TV, Goswami BN, Murthy BS, Kulkarni JR. 2011. Nocturnal low-level jet and "atmospheric streams" over the rain shadow region of indian western ghats. Quarterly Journal of the Royal Meteorological Society, 137(658), 1273-1287.

Prakash, S., Mitra, A.K., Rajagopal, E.N. and Pai, D.S. (2016), Assessment of TRMM-based TMPA-3B42 and GSM aP precipitation products over India for the peak southwest monsoon season. Int. J. Climatol., 36: 1614-1631. doi:10.1002/joc.4446

Preethi B, Revadekar JV, Kripalani RH. 2011. Anomalous behaviour of the Indian summer monsoon 2009. Journal of Earth System Science, 120(5), 783-794.

Rashki A, Kaskaoutis D G, Rautenbach C J W, et al. 2012. Dust storms and their horizontal dust loading in the Sistan region, Iran. Aeolian Research, 5, 51-62

Ranjha R, Tjernström M, Semedo A, Svensson G, Cardoso RM. 2015. Structure and variability of the Oman coastal low-level jet, Tellus, A: Dynamic Meteorology and Oceanography, 67:1, doi: 10.3402/tellusa.v67.25285.

Ramage CS. 1966. The Summer Atmospheric Circulation over the Arabian Sea. Journal of Atmospheric Sciences, 23, 144-150.

Ramaswamy V, Muraleedharan PM, Babu CP. 2017. Mid-troposphere transport of MiddleEast dust over the Arabian Sea and its effect on rainwater composition and sensitive ecosystems over India. Scientific Reports, 7(1), 1-8. 
Ratna SB, Ratnam JV, Behera SK, Tangang FT, Yamagata T. 2017. Validation of the WRF regional climate model over the subregions of Southeast Asia: Climatology and interannual variability. Climate Research, 71(3), 263-280.

Reshmi Mohan P, Srinivas CV, Yesubabu V, Baskaran R, Venkatraman B. 2018. Simulation of a heavy rainfall event over Chennai in Southeast India using WRF: Sensitivity to microphysics parameterization. Atmospheric Research, 210, 83-99.

Saha SK, Pokhrel S, Chaudhari HS, Dhakate A, Shewale S, Sabeerali CT, Salunke K, Hazra A, Mahapatra S, Rao AS. 2014. Improved simulation of Indian summer monsoon in latest NCEP climate forecast system free run. International Journal of Climatology, 34(5), 16281641.

Saha A, Ghosh S, Sahana AS, Rao EP. 2014a. Failure of CMIP5 climate models in simulating post-1950 decreasing trend of Indian monsoon. Geophysical Research Letters, 41(20), 7323-7330.

Samson G, Masson S, Lengaigne M, Keerthi MG, Vialard J, Pous S, Madec G, Jourdain NC, Jullien S, Menkes C, and Marchesiello P. 2014. The NOW regional coupled model: Application to the tropical Indian Ocean climate and tropical cyclone activity, J. Adv. Model. Earth Syst., 6, 700-722, doi:10.1002/2014MS000324.

Samson G, Masson S, Durand F, Terray P, Berthet S and Jullien S. 2017. Role of land surface albedo and horizontal resolution on the Indian Summer Monsoon biases in a coupled oceanatmosphere tropical-channel model. Climate dynamics, 48, 1571-1594.

Sooraj KP, Terray P, Masson S and Cretat J. 2019. Modulations of the Indian summer monsoon by the hot subtropical deserts: insights from sensitivity experiments. Climate Dynamics, 52, 4527-4555.

Seidel DJ, Ao CO, Li K. 2010. Estimating climatological planetary boundary layer heights from radiosonde observations: Comparison of methods and uncertainty analysis. Journal of Geophysical Research Atmosphere,s 115(16), 1-15. 
Sikka DR. 1980. Some aspects of the large-scale fluctuations of summer monsoon rainfall over India in realtion to fluctuations in the planetary and regional scale circulations. Proc. Indian Acad. Sci. Earth Planet. Sci,. 89(2), 179-195.

Sikka DR, Gray WM. 1981. Cross - hemispheric actions and the onset of the summer monsoon over India. International Conference on Scientific Results on Monsoon Experiments. Bali, Indonesia.

Skamarock WC, and Coauthors. 2008. A Description of the Advanced Research WRF Version 3. NCAR Technical Note NCAR/TN-475+STR, doi:10.5065/D68S4MVH.

Srinivas CV, Hariprasad D, Bhaskar Rao D V., Anjaneyulu Y, Baskaran R, Venkatraman B. 2013. Simulation of the Indian summer monsoon regional climate using advanced research WRF model. International Journal of Climatology, 33(5), 1195-1210.

Srinivas CV, Yesubabu V, Hari Prasad D, Hari Prasad KBRR, Greeshma MM, Baskaran R, and Venkatraman B. 2018. Simulation of an extreme heavy rainfall event over Chennai, India using WRF: sensitivity to grid resolution and boundary layer physics, Atmo. Res., 210, 66-82.

Swathi MS, Muraleedharan PM, Ramaswamy V, Rameshkumar MR, Aswini A. 2018. Upper air thermal inversion and their impact on the summer monsoon rainfall over Goa - A case study. Journal of Atmospheric and Solar-Terrestrial Physics, 169, 37-44.

Thakur MK, Lakshmi Kumar T V, Dwivedi S, Narayanan MS. 2018b. On the rainfall asymmetry and distribution in tropical cyclones over Bay of Bengal using TMPA and GPM rainfall products. Natural Hazards 94(2): 819-832. DOI: 10.1007/s11069-018-3426-5.

Thas O, Vooren L Van, Ottoy JP. 1998. Nonparametric test performance for trends in water quality with sampling design applications applications. JAWRA Journal of the American Water Resources Association,34(2),347-357. doi:10.1111/j.1752-1688.1998.tb04140.x.

Thompson G, Field PR, Rasmussen RM, Hall WD. 2008. Explicit Forecasts of Winter Precipitation Using an Improved Bulk Microphysics Scheme. Part II: Implementation of a New Snow Parameterization. Monthly Weather Review, 136(12), 5095-5115. 
Turner AG, Annamalai H. 2012. Climate change and the South Asian summer monsoon. Nature Climate Change, 2(8), 587-595.

Vinoj V, Rasch PJ, Wang H, Yoon J-H, Ma P-L, Landu K, Singh B. 2014. Short-term modulation of Indian summer monsoon rainfall by West Asian dust. Nature Geoscience, 7(4), 308-313.

Viswanadhapalli Y, Dasari HP, Langodan S, Challa VS, Hoteit I. 2017. Climatic features of the Red Sea from a regional assimilative model. Int J Climatol., 37(5), 2563-2581.

Viswanadhapalli Y, Dasari HP, Dwivedi S, Madineni VR, Langodan S, Hoteit I. 2019. Variability of monsoon low-level jet and associated rainfall over India. Int J Climatol.,40(2) 1067- 1089. https://doi.org/10.1002/joc.6256

Wang B, Liu J, Kim H-J, Webster PJ, Yim S-Y, Xiang B. 2013. Northern Hemisphere summer monsoon intensified by mega-El Nino/southern oscillation and Atlantic multidecadal oscillation. Proceedings of the National Academy of Sciences, 110(14), 5347-5352.

Warnecke G, Allison LJ, McMillin LM, Szekielda K-H. 1971. Remote sensing of ocean currents and sea surface temperature changes derived from the Nimbus II satellite. Journal of Physical Oceanography, 1(1), 45-60.

Wu CH, Wang SYS, Hsu HH. 2018. Large-scale control of the Arabian Sea monsoon inversion in August. Climate Dynamics, 51(7-8), 2581-2592. doi: 10.1007/s00382-0174029-7.

Yu Y, Notaro M, Kalashnikova OV, Garay MJ. 2016. Climatology of summer Shamal wind in the Middle East. Journal of Geophysical Research, 121(1), 289-305.

Zaz SN, Shakil Ahmad R, Krishnamoorthy RT, Viswanadhapalli Y. 2018. Climatic and extreme weather variations over Mountainous Jammu and Kashmir, India: Physical explanations based on observations and modelling. Atmospheric Chemistry and Physics Discussions, 2018: 1-47. 


\section{List of Figures}

Figure GA. a) Schematic diagram of prevailing wind pattern during Indian Summer Monsoon season and the left panels indicate trends in b) the wind speed anomalies at 950-hPa level, (c) $\Delta \mathrm{T}(\mathrm{K})$ between 850 - 950 hPa levels and (d) daily Percentage Occurrence of Monsoon inversion over the WAS and EAS regions.

Figure 1. a) WRF model domain (left panel) along with topography of the study region, b) The locations of radiosonde data (circles in red color) and areas selected for the western (WAS) and eastern (EAS) Arabian Sea used for the analysis.

Figure 2. Mean JJAS profiles of temperature and wind at four selected locations (Salalah, Mumbai, Goa and Mangalore) from WRF and radiosonde data for the whole study period (1980-2016).

Figure 3. Monthly climatology of percentage occurrence of MI (y-axis) estimated from WRF model and radiosonde data at Salalah station for the period from 1980 to 2016. The x-axis indicates the inversion heights.

Figure 4. 37-year mean JJAS winds (magnitude shown in shaded and direction in vector) from MERRA2, ERA-I and WRF for $950 \mathrm{hPa}$ and $850 \mathrm{hPa}$, and the temperature inversion $(\Delta \mathrm{T}$, shaded in color) and wind shear (in vector) between 950 and $850 \mathrm{hPa}$ levels.

Figure 5. Pressure-longitude sections of 37-year mean JJAS temperature lapse rate (K per $25 \mathrm{hPa}$ ) and winds (shown in vector) at $12^{\circ} \mathrm{N}, 16^{\circ} \mathrm{N}, 20^{\circ} \mathrm{N}$, and $24^{\circ} \mathrm{N}$ latitudes from MERRA2, ERA-I and WRF.

Figure 6. 37-year mean lapse rate ( $\Delta \mathrm{T}$ between 950 and $850 \mathrm{hPa}$ shown in shaded) and wind shear (in vector) computed between 950 and $850 \mathrm{hPa}$ (top panels) and corresponding monthly rainfall (bottom panels) from WRF simulations for June, July, August and September.

Figure 7. 37-year mean monthly (from May to September) advection at $975 \mathrm{hPa}$ (left panels) and 925 $\mathrm{hPa}$ (middle panels) and convection (right panels) at 700 - $400 \mathrm{hPa}$ computed from WRF simulations.

Figure 8. 37-year mean advection at $800 \mathrm{hPa}$ to $975 \mathrm{hPa}$ from MERRA2 (left panels), ERA-I (middle panels) and WRF (right panels).

Figure 9. 37-year mean lapse rate ( $\Delta \mathrm{T}$ between 950 and $850 \mathrm{hPa}$ ) during JJAS at (a) $0000 \mathrm{UTC}$, (b) 0600 UTC, (c) 1200 UTC, and (d) 1800 UTC from WRF simulations.

Figure 10. 37-year mean diurnal variation of wind shear (magnitude shown in shaded and direction in vector) computed between 950 and $850 \mathrm{hPa}$ during JJAS at (a) 0000 UTC, (b) 0600 UTC, (c) 1200 UTC, and (d) 1800 UTC from WRF simulations. The gray-shades represent the topography (intense color indicates higher terrain). 
Figure 11. Pressure-longitude sections of 37-year mean lapse rates (K per $25 \mathrm{hPa}$, shaded in color) and winds (in vector) during JJAS at (a) 0000 UTC, (b) 0600 UTC, (c) 1200 UTC, and (d) 1800 UTC. The white and pink arrows differentiate winds below and above $10 \mathrm{~ms}^{-1}$, respectively.

Figure 12. Trends in SLP (hPa per year, top panels), wind shear between 950 and $850 \mathrm{hPa}(\mathrm{m} / \mathrm{s}$ per year, middle panels), and $\Delta \mathrm{T}$ (K per year, lower panel) estimated from ERA-I (left panels) and WRF (right panels).

Figure 13. Time series of (a) mean lapse rate ( $\Delta \mathrm{T}$ in $\mathrm{K}$ between 950 and $850 \mathrm{hPa}$ ) and (b) daily percentage occurrence of MI from WRF over the WAS and EAS.

\section{List of Supportive Figures}

Figure S1. Spatial distribution of 37-year mean (a) CAPE, (b) CIN, (c) Latent heat flux, and (d) sensible heat flux using JJAS from WRF outputs.

Figure S2. The spatial distribution of JJAS rainfall (accumulated in mm) obtained from TRMM-3B42V7 estimates and WRF outputs.

Figure S3. The diurnal variation of $\Delta \mathrm{T}$ and Wind Shear computed between 950 and $850 \mathrm{hPa}$ obtained from WRF outputs averaged over the WAS $\left(17^{\circ} \mathrm{N}-21^{\circ} \mathrm{N}, 58^{\circ} \mathrm{E}-61^{\circ} \mathrm{E}\right)$.

Figure S4. Spatial distribution of 37-year mean winds at 950 and $850 \mathrm{hPa}$ from ERA-I and WRF outputs.

Figure S5. Time series of WRF wind speed anomaly at a) $850 \mathrm{hPa}$ and b) $950 \mathrm{hPa}$ averaged over the WAS $\left(17^{\circ} \mathrm{N}-21^{\circ} \mathrm{N}, 58^{\circ} \mathrm{E}-61^{\circ} \mathrm{E}\right)$ and the EAS $\left(17^{\circ} \mathrm{N}-21^{\circ} \mathrm{N}\right.$ and $69{ }^{\circ} \mathrm{E}-72$ $\left.{ }^{\circ} \mathrm{E}\right)$. 


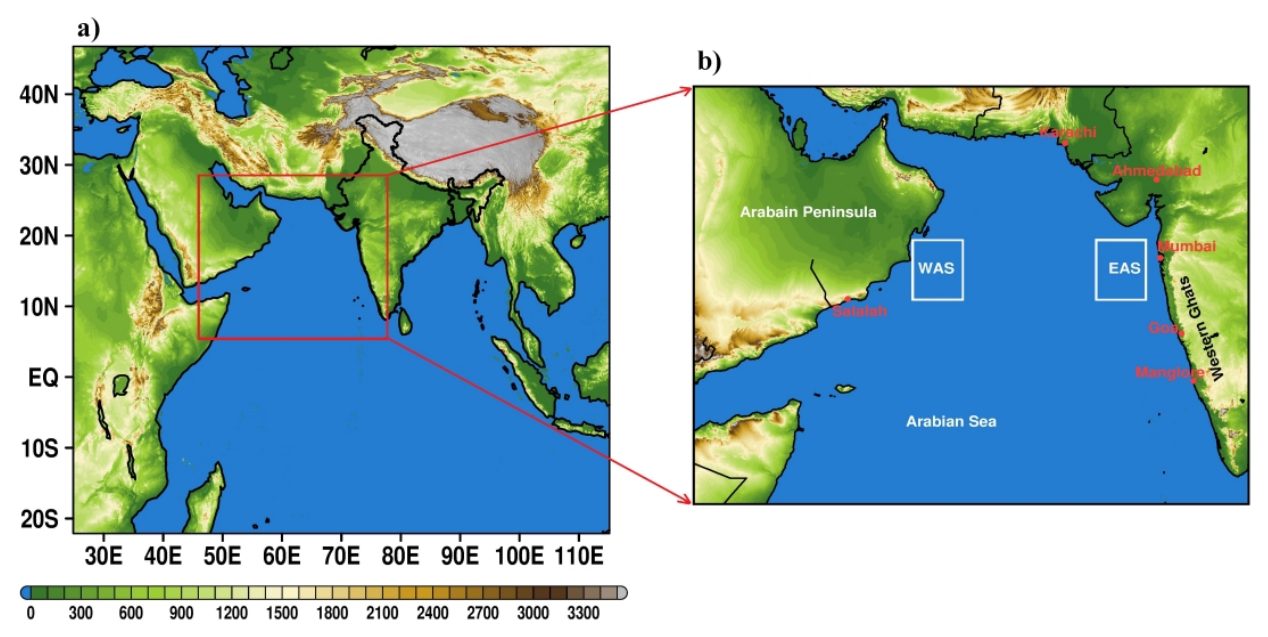

Figure 1. a) WRF model domain (left panel) along with topography of the study region, b) The locations of radiosonde data (circles in red color) and areas selected for the western (WAS) and eastern (EAS) Arabian Sea used for the analysis.

$1828 \times 889 \mathrm{~mm}(72 \times 72$ DPI $)$

This article is protected by copyright. All rights reserved. 

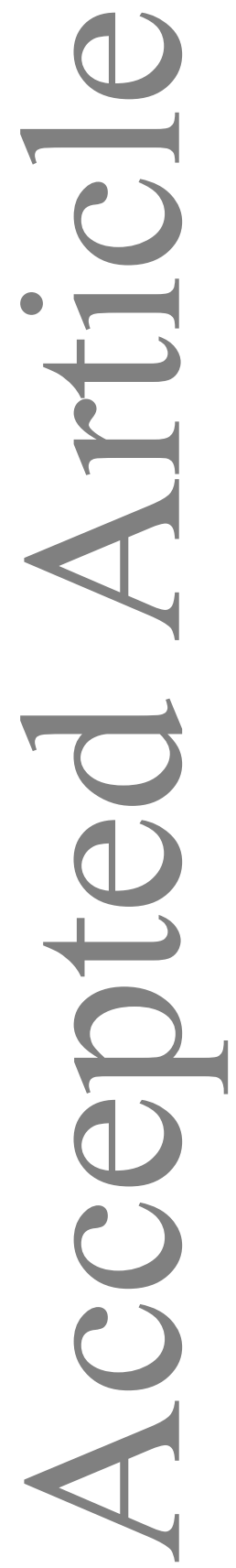
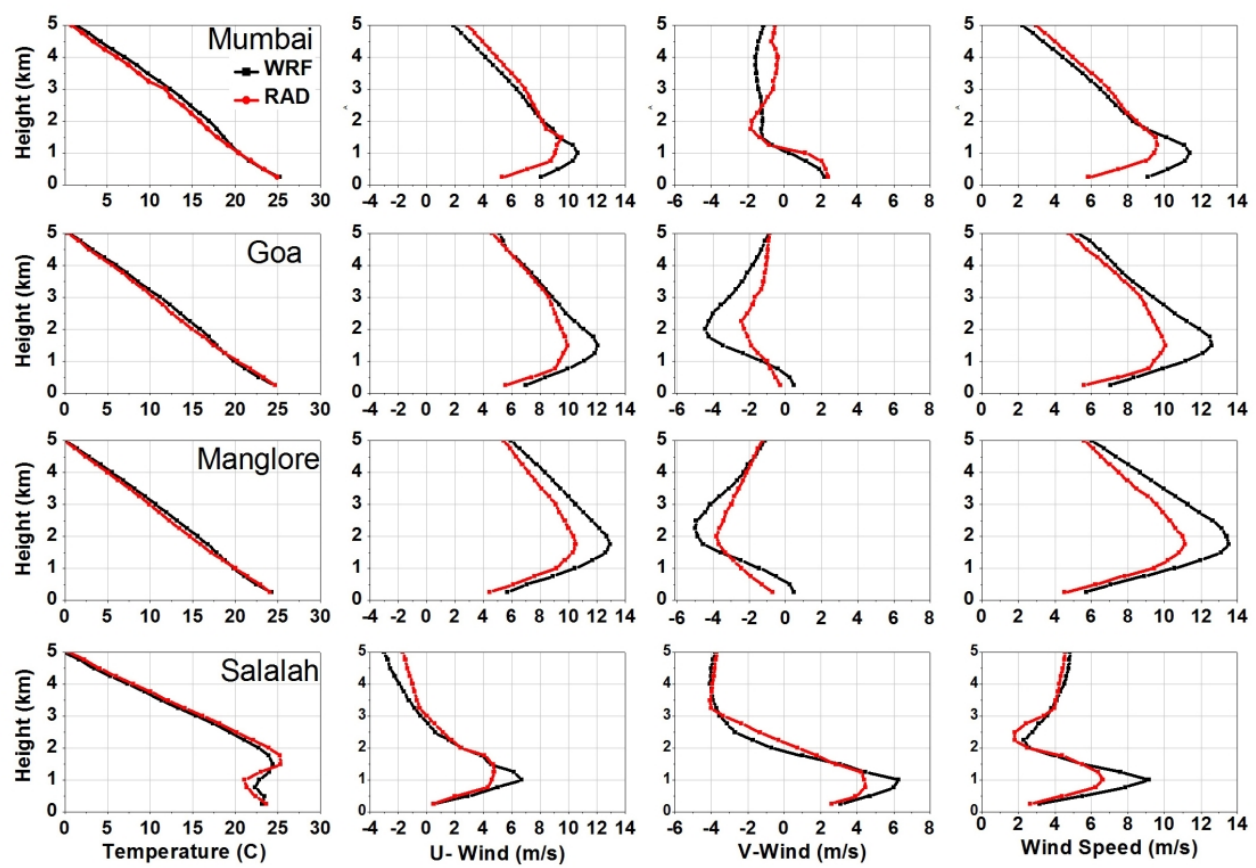

Figure 2. Mean JJAS profiles of temperature and wind at four selected locations (Salalah, Mumbai, Goa and Mangalore) from WRF and radiosonde data for the whole study period (1980-2016).

$$
186 \times 125 \mathrm{~mm}(300 \times 300 \mathrm{DPI})
$$

This article is protected by copyright. All rights reserved. 

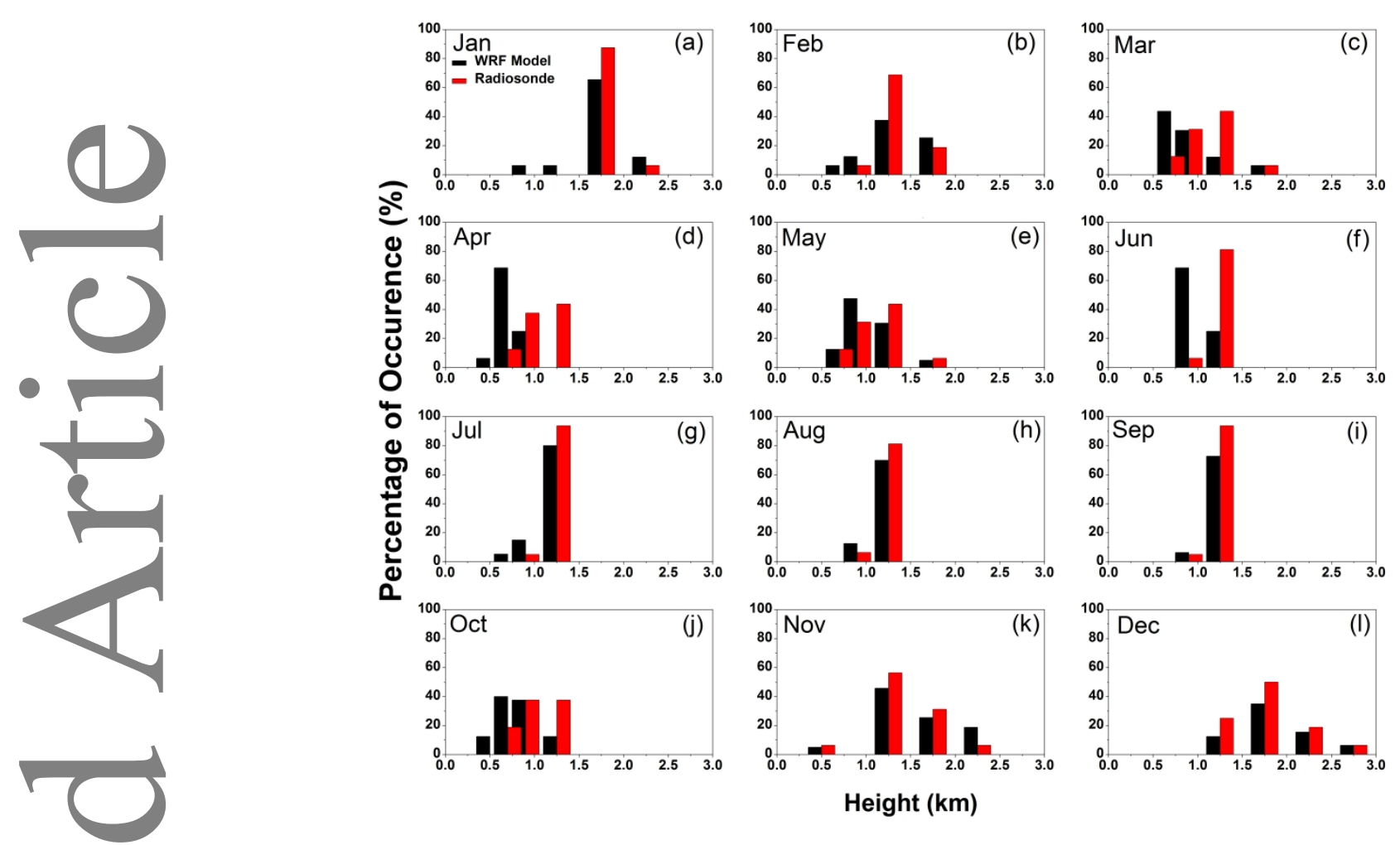

Height (km)

Figure 3. Monthly climatology of percentage occurrence of MI (y-axis) estimated from WRF model and radiosonde data at Salalah station for the period from 1980 to 2016 . The x-axis indicates the inversion heights.

$516 \times 399 \mathrm{~mm}(300 \times 300 \mathrm{DPI})$

This article is protected by copyright. All rights reserved. 


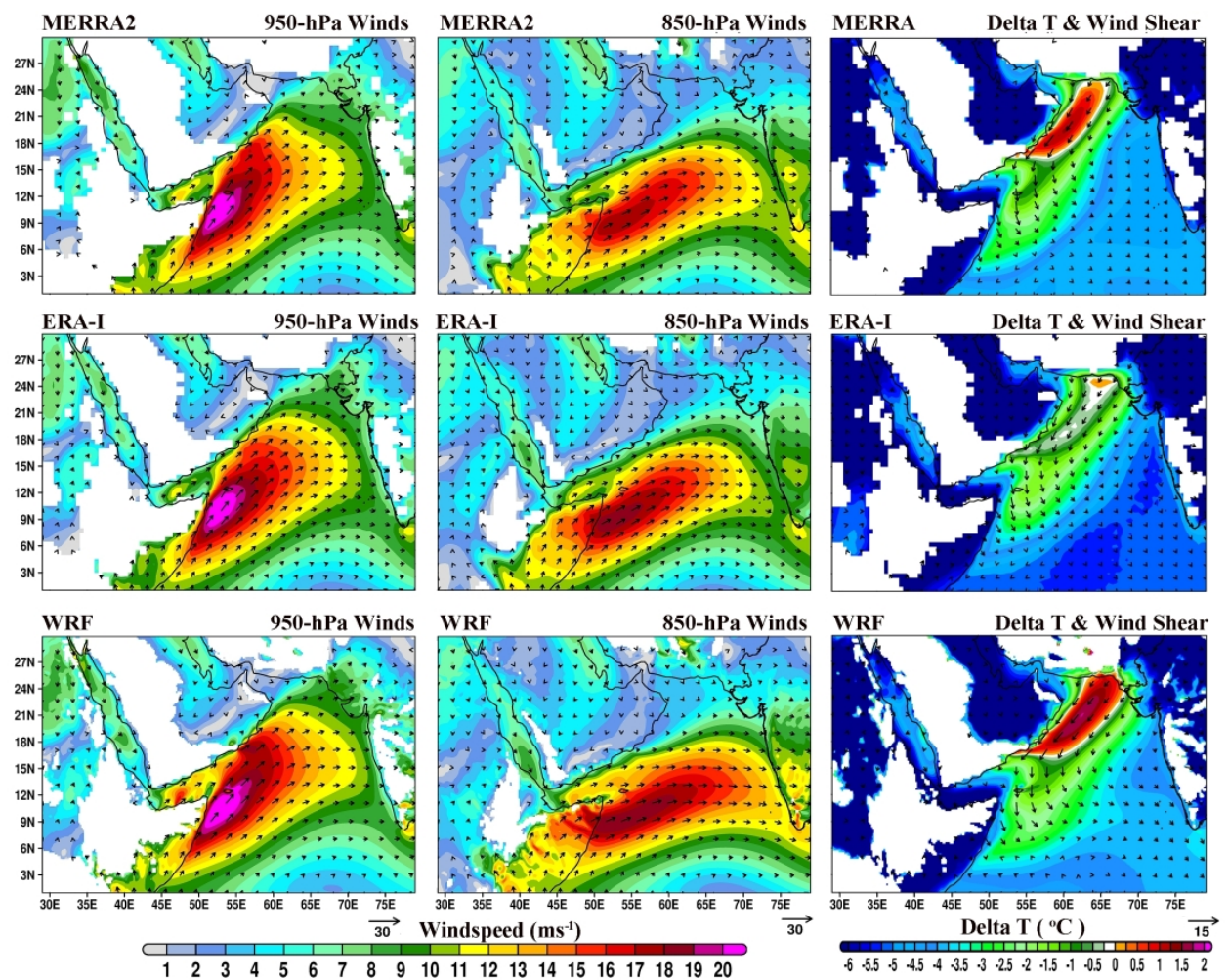

Figure 4. 37-year mean JJAS winds (magnitude shown in shaded and direction in vector) from MERRA2, ERA-I and WRF for $950 \mathrm{hPa}$ and $850 \mathrm{hPa}$, and the temperature inversion $(\Delta \mathrm{T}$, shaded in color) and wind shear (in vector) between 950 and $850 \mathrm{hPa}$ levels.

$283 \times 226 \mathrm{~mm}(300 \times 300 \mathrm{DPI})$

This article is protected by copyright. All rights reserved. 

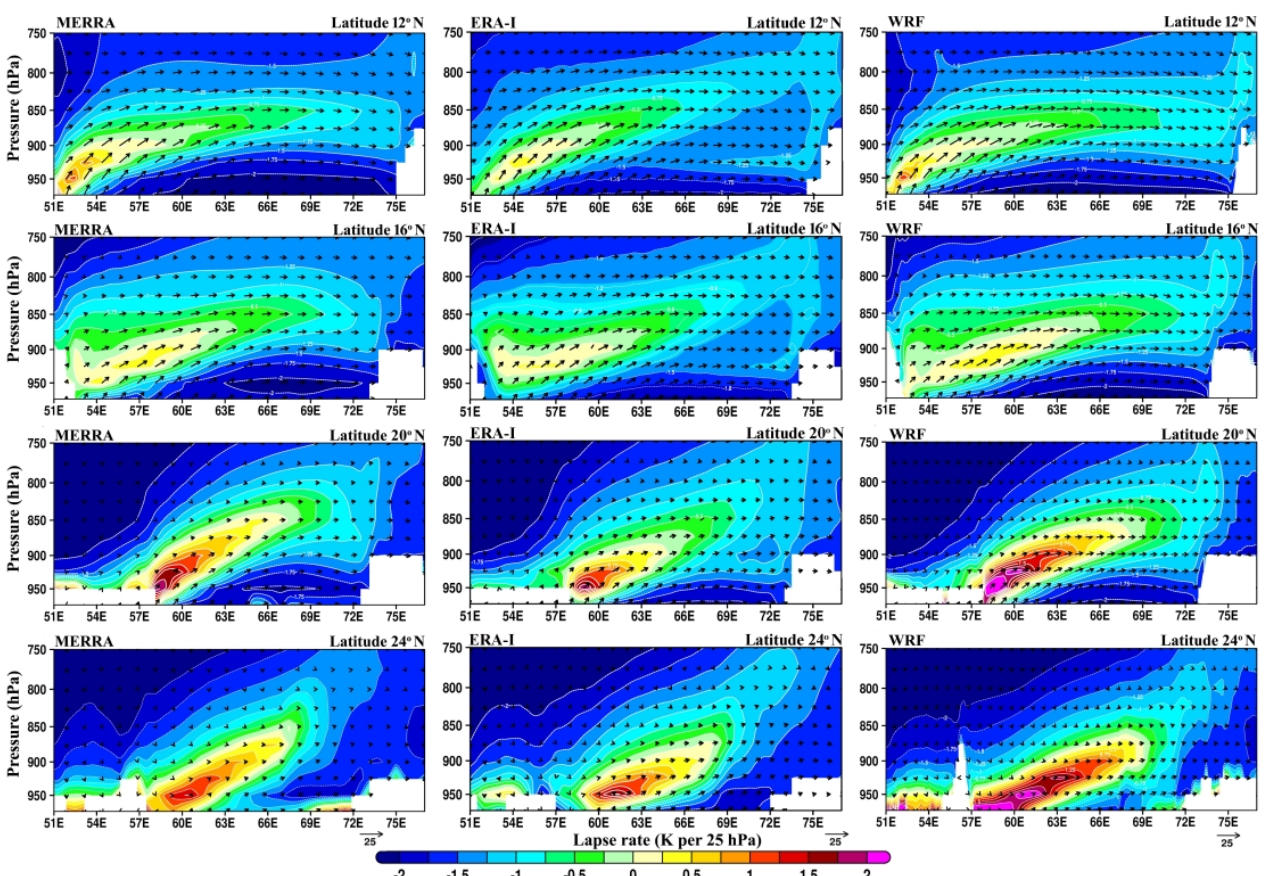

Figure 5. Pressure-longitude sections of 37-year mean JJAS temperature lapse rate ( $\mathrm{K}$ per $25 \mathrm{hPa}$ ) and winds (shown in vector) at $120 \mathrm{~N}, 160 \mathrm{~N}, 200 \mathrm{~N}$, and $240 \mathrm{~N}$ latitudes from MERRA2, ERA-I and WRF. 

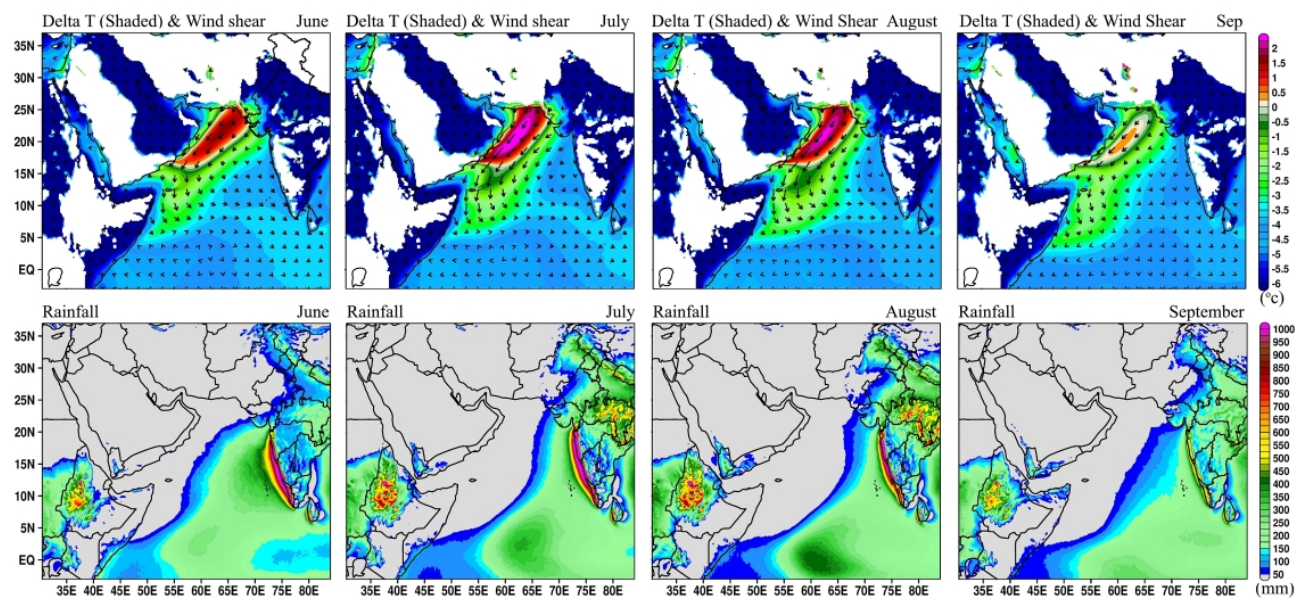

Figure 6. 37-year mean lapse rate ( $\Delta \mathrm{T}$ between 950 and $850 \mathrm{hPa}$ shown in shaded) and wind shear (in vector) computed between 950 and $850 \mathrm{hPa}$ (top panels) and corresponding monthly rainfall (bottom panels) from WRF simulations for June, July, August and September.

$$
300 \times 142 \mathrm{~mm}(300 \times 300 \mathrm{DPI})
$$

This article is protected by copyright. All rights reserved. 


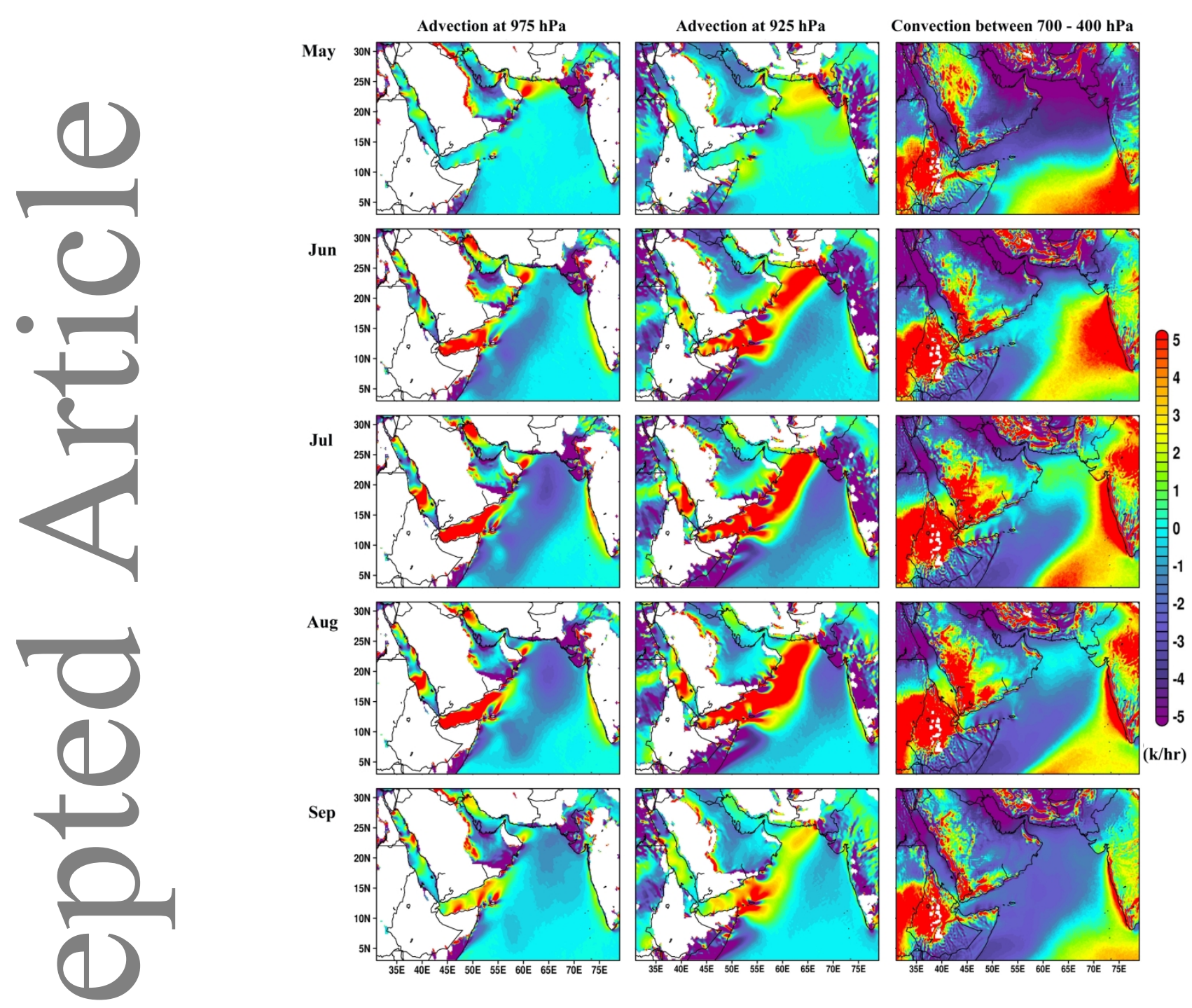

Figure 7. 37-year mean monthly (from May to September) advection at $975 \mathrm{hPa}$ (left panels) and $925 \mathrm{hPa}$ (middle panels) and convection (right panels) at $700-400 \mathrm{hPa}$ computed from WRF simulations. 


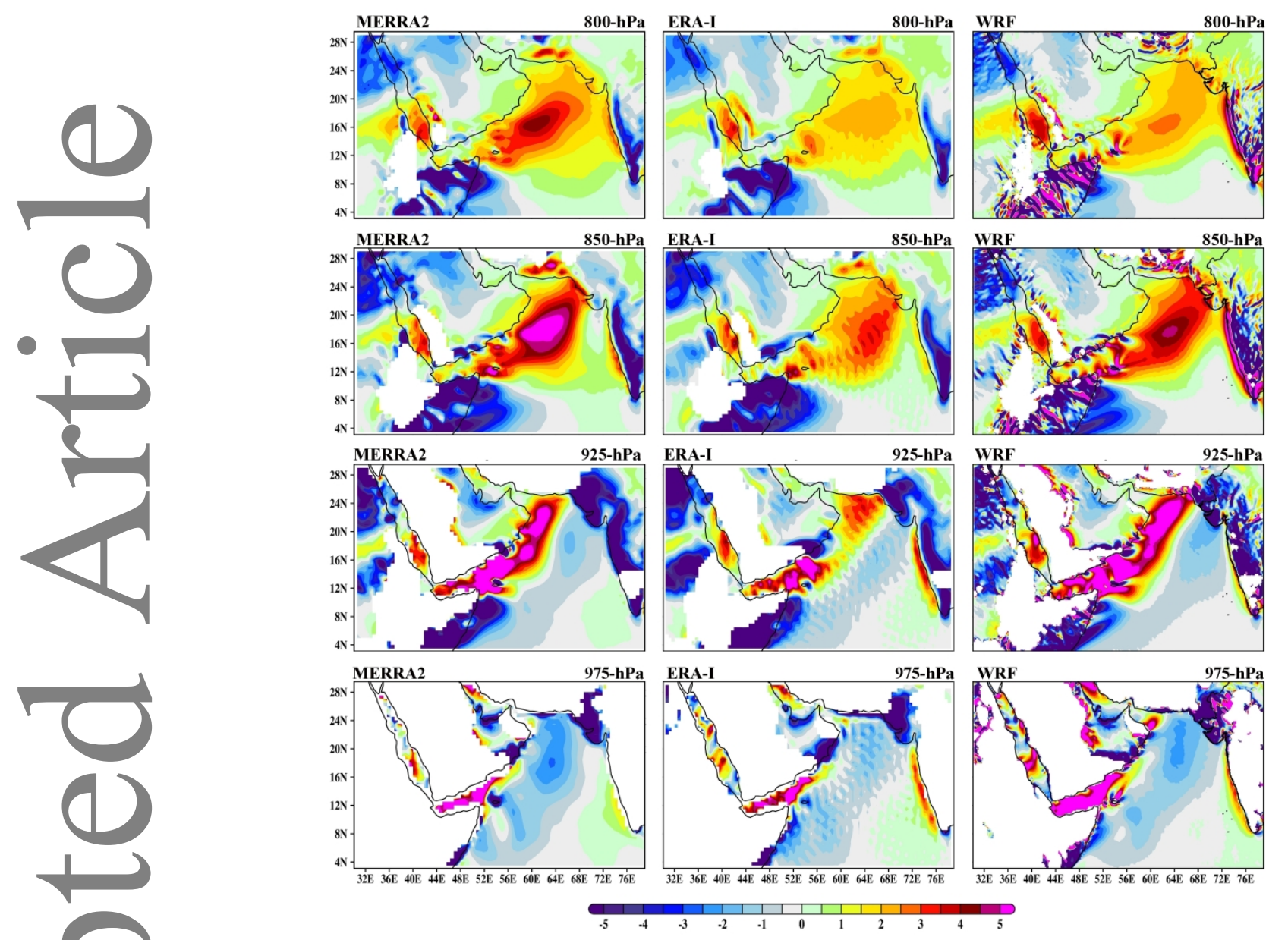

Figure 8. 37-year mean advection at $800 \mathrm{hPa}$ to $975 \mathrm{hPa}$ from MERRA2 (left panels), ERA-I (middle panels) and WRF (right panels).

$264 \times 251 \mathrm{~mm}(300 \times 300 \mathrm{DPI})$

This article is protected by copyright. All rights reserved. 
a) 0000 UTC

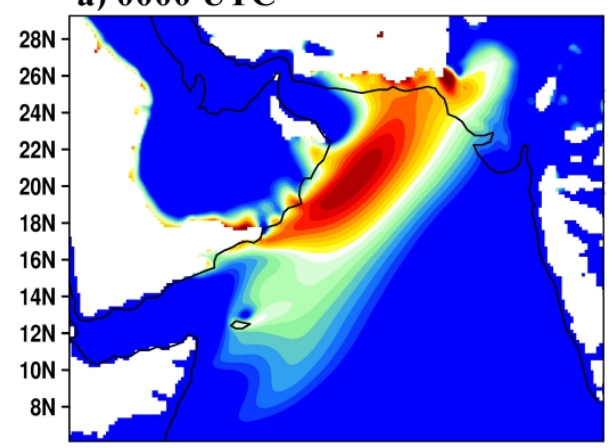

c) 1200 UTC

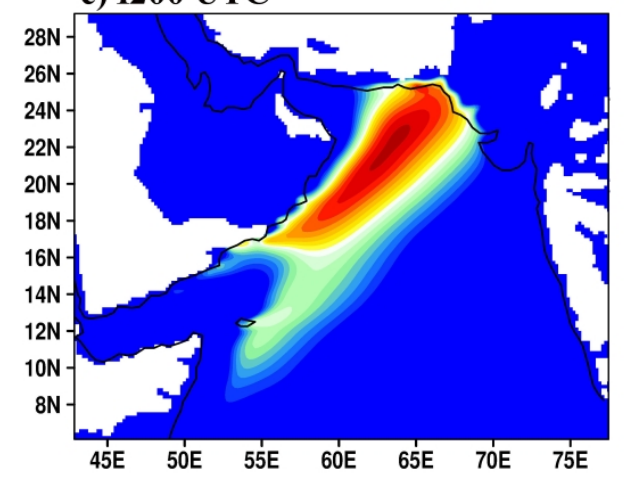

b) 0600 UTC

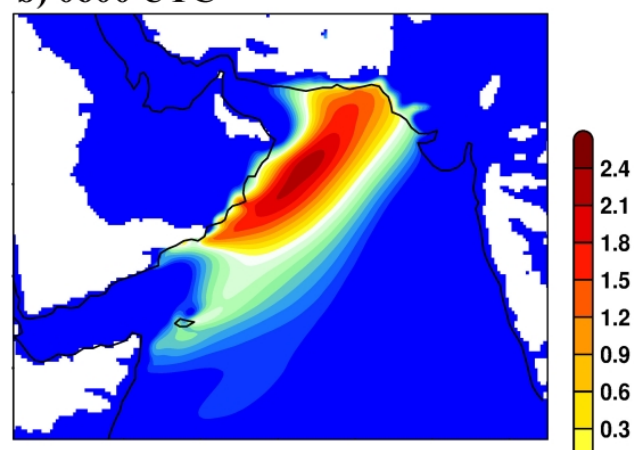

d) 1800 UTC

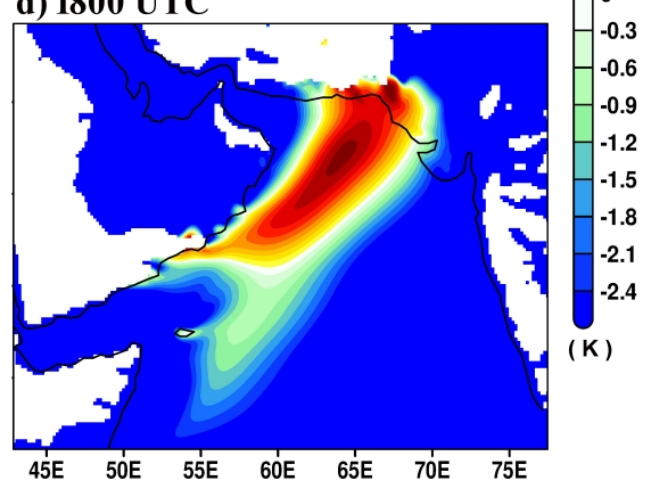

Figure 9. 37-year mean lapse rate ( $\Delta \mathrm{T}$ between 950 and $850 \mathrm{hPa}$ ) during JJAS at (a) $0000 \mathrm{UTC}$, (b) 0600 UTC, (c) 1200 UTC, and (d) 1800 UTC from WRF simulations.

$2032 \times 1583 \mathrm{~mm}(72 \times 72 \mathrm{DPI})$ 
a) 0000 UTC

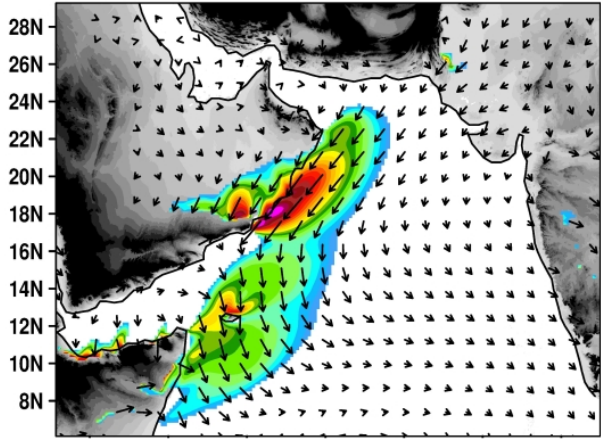

c) 1200 UTC

$28 \mathrm{~N}-$
$26 \mathrm{~N}-$
$24 \mathrm{~N}-$
$22 \mathrm{~N}$
$20 \mathrm{~N}-$
$18 \mathrm{~N}$
$16 \mathrm{~N}-$
$14 \mathrm{~N}$
$12 \mathrm{~N}$
$10 \mathrm{~N}$
$8 \mathrm{~N}-$
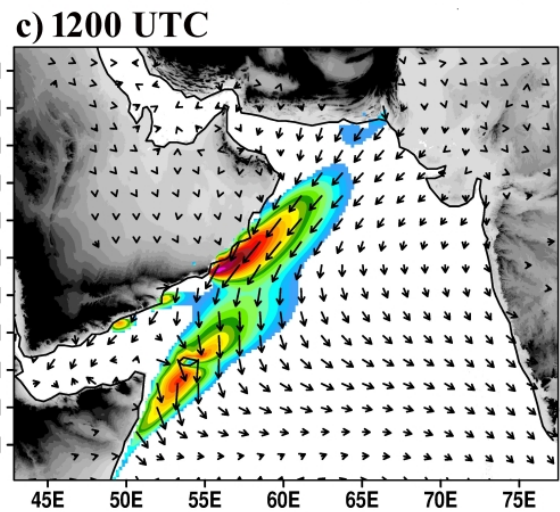

b) 0600 UTC

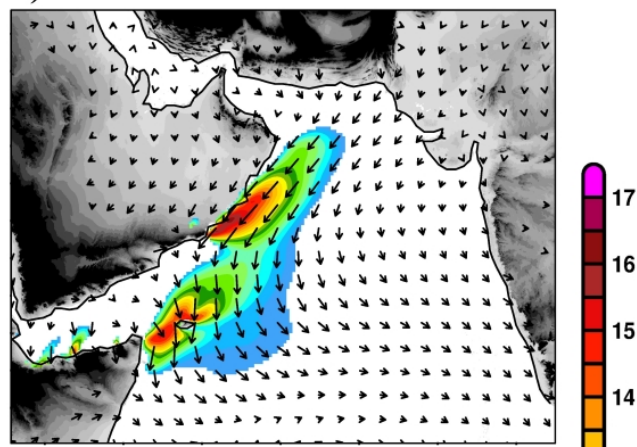

d) 1800 UTC
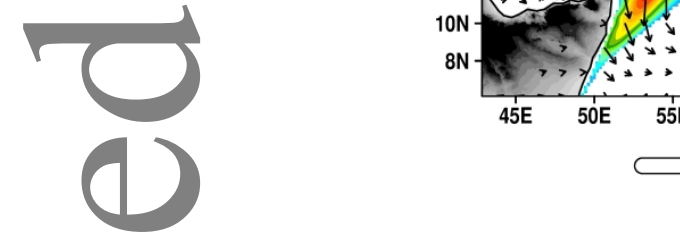

Figure 10. 37-year mean diurnal variation of wind shear (magnitude shown in shaded and direction in vector) computed between 950 and $850 \mathrm{hPa}$ during JJAS at (a) 0000 UTC, (b) 0600 UTC, (c) 1200 UTC, and

(d) 1800 UTC from WRF simulations. The gray-shades represent the topography (intense color indicates higher terrain).

$478 \times 405 \mathrm{~mm}(300 \times 300 \mathrm{DPI})$

This article is protected by copyright. All rights reserved. 

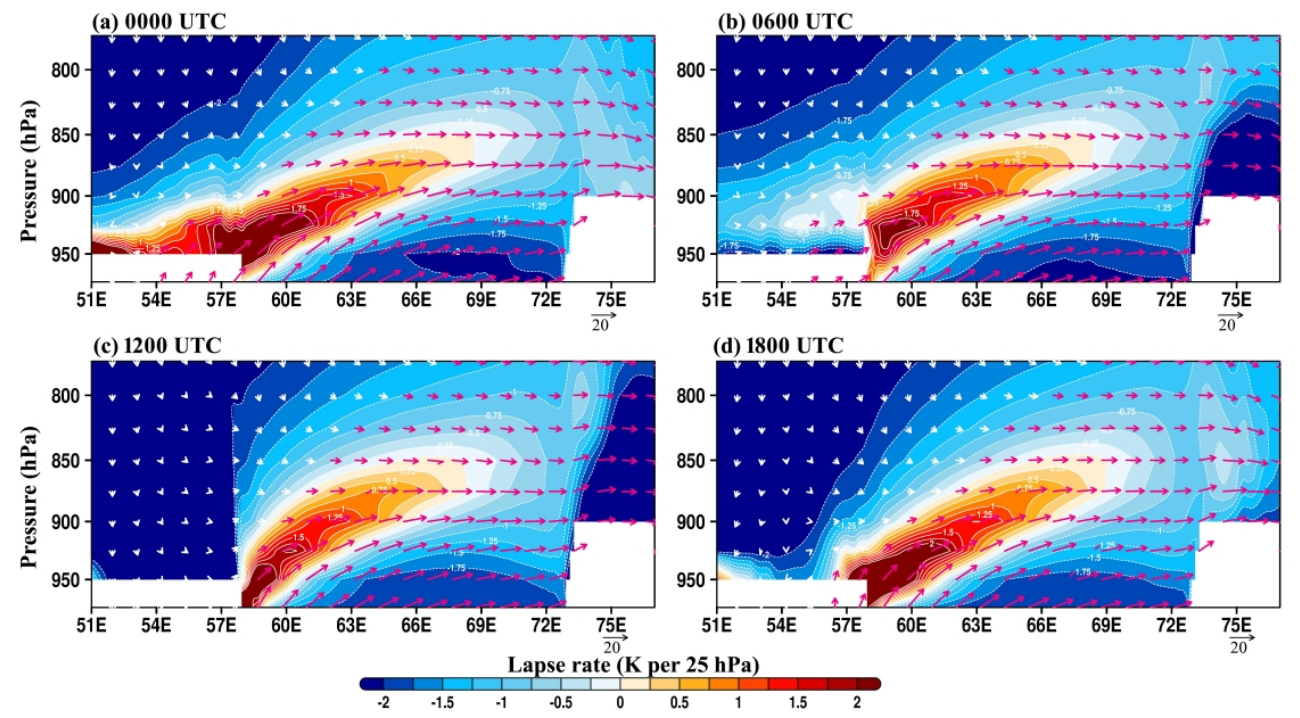

Figure 11. Pressure-longitude sections of 37-year mean lapse rates ( $\mathrm{K}$ per $25 \mathrm{hPa}$, shaded in color) and winds (in vector) during JJAS at (a) 0000 UTC, (b) 0600 UTC, (c) 1200 UTC, and (d) 1800 UTC. The white and pink arrows differentiate winds below and above $10 \mathrm{~ms}-1$, respectively.

$2212 \times 1261 \mathrm{~mm}(72 \times 72 \mathrm{DPI})$

This article is protected by copyright. All rights reserved. 

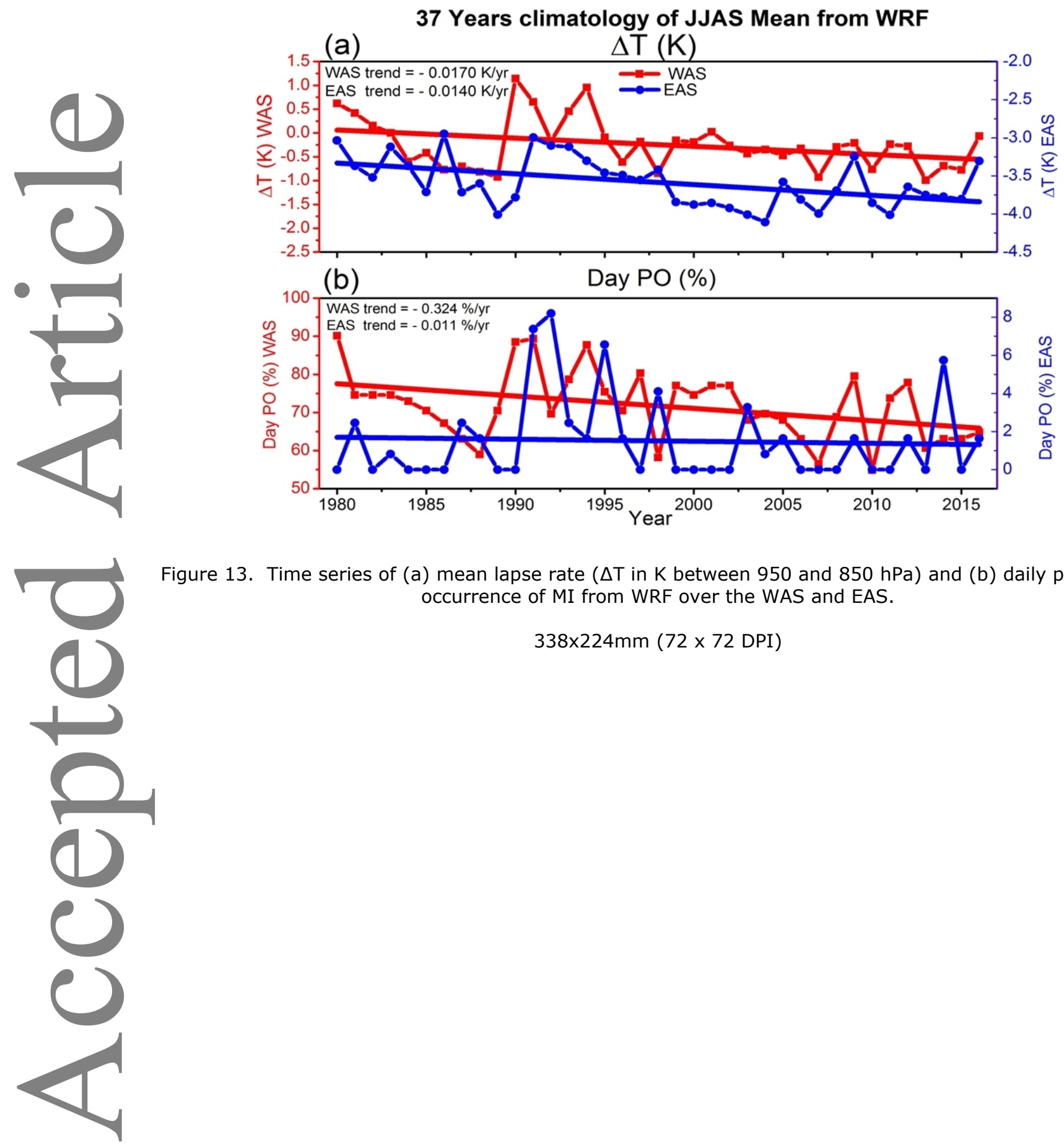

Figure 13. Time series of (a) mean lapse rate ( $\triangle \mathrm{T}$ in $\mathrm{K}$ between 950 and $850 \mathrm{hPa})$ and (b) daily percentage occurrence of MI from WRF over the WAS and EAS.

$338 \times 224 \mathrm{~mm}(72 \times 72$ DPI $)$

This article is protected by copyright. All rights reserved. 